\title{
SECTION II
}

PHYSICAL PROCESSES IN PLANETARY NEBULAE 
RECENT ADVANCES IN ATOMIC CALCULATIONS AND EXPERIMENTS OF INTEREST IN THE STUDY OF PLANETARY NEBULAE

\section{MENDOZA}

Department of Physics and Astronomy, University College London, Gower Street, London WC1E 6BT.

Present address: Departamento de Fisica y Matematicas, Universidad Simon Bolivar, PO Box 80659, Caracas, Venezuela.

\section{ABSTRACT}

Recent advances in the calculation and measurement of transition probabilities, electron excitation rate coefficients and photoionization cross sections relevant to the study of planetary nebulae are discussed. A compilation of these parameters is also presented.

\section{INTRODUCTION}

Planetary nebulae are, in a sense, rich and challenging atomic physics laboratories. The low electron temperatures and densities of the nebular envelope give rise to a variety of atomic processes which are difficult to reproduce and measure in more accessible laboratories. The atomic data required to interpret these phenomena are therefore mainly obtained by calculation, where a clear understanding is necessary followed by an enormous computational effort. In the last decade several sophisticated computer packages have been developed to calculate atomic data with these points in mind. Advances in computer technology, such as the introduction of the CRAY-1 vector processor, have enabled a high degree of accuracy to be reached for the simpler ions, the possibility to treat consistently ions of the second row of the periodic table, and to make firm introductory attempts in the study of the larger ions such as those of iron.

In the present paper we review briefly recent developments made in the calculation and measurement of transition probabilities, electron excitation rate coefficients and photoionization cross sections. A compilation of these parameters is given in the Appendix.

\section{TRANSITION PROBABILITIES}

The calculation of accurate transition probabilities for forbidden and semi-forbidden lines, such as those found in nebular spectra, must 
include the relativistic interaction and electron correlation effects. For light ions, where relativistic effects are small, the relativistic interaction can be treated as a perturbation by considering the Hamiltonian

$$
\mathrm{H}=\mathrm{H}_{\mathrm{NR}}+\mathrm{H}_{\mathrm{BP}}
$$

where $H_{N R}$ is the non-relativistic Hamiltonian and $H_{B P}$ is the Breit-Pauli relativistic correction ${ }^{1}$. The relativistic wave function $\psi_{i}(R)$ can then be expanded in terms of the non-relativistic wave functions $\psi_{j}(N R)$ thus

$$
\psi_{i}(R)=\psi_{i}(N R)+\sum_{j \neq i} \psi_{j}(N R) \frac{\left\langle\psi_{j}(N R)\left|H_{B P}\right| \psi_{i}(N R)\right\rangle}{E_{i}(N R)-E_{j}(N R)} \cdots
$$

Electron correlation effects are usually included by the method of configuration interaction (CI). The NR wave functions are linearly expanded in a configuration basis of the form

$$
\psi(N R)=\sum_{k} c_{k} \phi_{k}
$$

where the configuration functions $\phi_{k}$ are built from one-electron orbitals. The convergence of the CI expansion can be slow and the transition probabilities of forbidden and semi-forbidden transitions are usually sensitive to the number of configurations in the CI expansion. In most cases configurations containing one-electron pseudo-orbitals, i.e. artificial orbitals adjusted variationally to improve term energy separations or fine-structure energy splittings, must be considered. Furthermore, if a high degree of accuracy is desired small semi-empirical adjustments cannot be avoided. For instance, Zeippen et $a 1 .{ }^{2}$ introduce semi-empirical term energy corrections such that $\psi(R)$ are calculated with the "exact" NR energies in equation (2), and calculate the A-values with the experimental energy level separations.

In the past these interactions were mainly treated by semi-empirical methods with a fair amount of success. Work such as that by Garstang ${ }^{3}$, Czyzak and Krueger ${ }^{4}$ and McKim-Malville and Berger ${ }^{5}$ on forbidden lines, and Laughlin and Victor ${ }^{6}$ on intercombination 1 ines have provided reliable results for many years. The present trend is to carry out large CI calculations where such interactions are included more rigorously.

Perhaps the most significant recent theoretical development made in connection with transition probabilities relevant to planetary nebulae is that by Eissner and Zeippen ${ }^{7}$ on the transition probabilities for forbidden lines within the $\mathrm{np}^{3}$ configuration of the nitrogen and phosphorus isoelectronic sequences. They have shown that higher-order relativistic corrections to the magnetic dipole operator ${ }^{8}$ (up to order $\alpha^{2} z^{2}$ ), which are usually 
negligible, must be taken into account in order to obtain accurate A-values for the low members of the sequence, and thereby ending a long-standing discrepancy between the observed and theoretical values for the density sensitive line intensity ratio

$$
r\left(N_{e}\right)=I\left({ }^{2} D_{2}^{0}-{ }^{4} S_{3}^{0}\right) / I\left({ }^{2} D_{\frac{3}{2}}^{0}-{ }^{4} S_{\frac{3}{2}}^{0}\right)
$$

in the high density limit. For $\mathrm{N}_{e} \rightarrow \infty$

$$
r(\infty)=\frac{3}{2} A\left({ }^{2} D_{\frac{5}{2}}^{0}-{ }^{4} S_{\frac{3}{2}}^{0}\right) / A\left({ }^{2} D_{\frac{3}{2}}^{0}-{ }^{4} S_{\frac{3}{2}}^{0}\right)
$$

where $A(i-j)$ is the transition probability, and thus provides a useful comparison between observation and theory. In table 1 we compare $r(\infty)$ for $\mathrm{N}^{\circ}, \mathrm{O}^{+}$and $\mathrm{S}^{+}$calculated in this way (MZ) with previous theoretical results (G) and observations (OBS).

\begin{tabular}{lrrr}
\hline ION & OBS & MZ & G \\
\hline $\mathrm{N}^{\circ}$ & $\lesssim 0.51$ & 0.54 & 0.65 \\
$\mathrm{O}^{+}$ & 0.35 & 0.35 & 0.42 \\
$\mathrm{~S}^{+}$ & 0.45 & 0.44 & 0.39 \\
\hline
\end{tabular}

TABLE 1. Observed and theoretical values for $r(\infty)$ (see text). OBS(ref. $9,10), M Z($ ref. 11,12$)$ and $G($ ref. 3).

Also in connection with forbidden lines, Nussbaumer and Rusca ${ }^{13}$, Zeippen ${ }^{11}$ and Mendoza and Zeippen ${ }^{12}$ have carried out extensive calculations of A-values for transitions within the npq configurations $(n=2-3 ; q=2-4$; $\mathrm{Z}=6-28$ ), examining the importance of $\mathrm{CI}$, relativistic corrections and semi-empirical adjustments. They have improved substantially on the ear1ier semi-empirical results compiled by Garstang ${ }^{3}$ and McKim-Malville and Berger ${ }^{5}$. Nussbaumer and Storey ${ }^{14}$ are systematically studying the ions of $\mathrm{Fe}$.

There have been a considerable number of detailed calculations on the intercombination lines of astrophysical interest. The work of Glass and Hibbert ${ }^{15}$ and Nussbaumer and Storey ${ }^{16}$ on the Be-like ions may be chosen to illustrate the main features of these calculations. They demonstrate the high sensitivity of the transition probabilities to the values of small coefficients $c_{k}$ of the CI expansion, and stress the need to use large configuration bases containing pseudo-orbitals and to make semiempirical term energy corrections. Although different numerical methods 
are used the agreement is better than $10 \%$, in marked contrast with recent work by Cowan et al. ${ }^{17}$ on $f$-values for astrophysical intercombination lines where limited configuration bases are used and an accuracy of only $50 \%$ is claimed.

Even though a perturbative treatment of the relativistic interaction for light ions can be regarded as satisfactory, there are also numerical methods based on the more formal solution of the Dirac equation. Hata and Grant ${ }^{18}$ have used the multi-configuration Dirac-Fock method, which allows for correlation effects, to compute the lifetime of the astrophysically important $2^{3} \mathrm{~S}$ state of $\mathrm{He}^{\mathrm{O}}$. They obtain a value of $8.8 \times 10^{3}$ sec in close agreement with the experimental result ${ }^{19}$ of $9 \pm 3 \times 10^{3} \mathrm{sec}$. This method has also been used recent $1 y^{20}$ to compute a large number of E1, E2 and M1 transition probabilities within the $n=2$ complex with moderate accuracy for low $Z$.

The experimental techniques employed to measure lifetimes for allowed transitions are in general not suited for forbidden transitions and, consequently, there have been few experimental results. Corney and Williams ${ }^{21}$ have measured the radiative decay constant of the ${ }^{1} S_{0}$ metastable state of $0^{\circ}$ by the pulsed afterglow method. They obtain $\Gamma_{\text {expt }}=1.31 \pm 0.05$ $\mathrm{sec}^{-1}$ in excellent agreement with preliminary results by Mendoza and Zeippen of $\Gamma_{\text {th }}=1.29 \mathrm{sec}^{-1}$ using the CI method. There is also a new interesting technique being developed by Nightingale 22 to measure transition probabilities for forbidden lines of singly-ionized species. He is trying to measure the $A-v a l u e$ for the ${ }^{1} S_{0}-{ }^{1} D_{0}(\lambda 5754)$ transition of $\mathrm{N}^{+}$by the long-path absorption spectroscopy method. Due to the small ionic absorption coefficients optical paths greater than $1 \mathrm{Km}$ are required which he obtains by using a plasma source ten metres long and a multiplepass optical laser system.

\section{ELECTRON EXCITATION RATE COEFFICIENTS}

Some of the problems encountered in the calculation of electron impact excitation cross sections of positive ions of astrophysical interest have been discussed by Mendoza ${ }^{23}$. The electron excitation rate coefficient for a transition between levels $j \rightarrow i(i>j)$ at an electron temperature $\mathrm{T}_{\mathrm{e}}$ can be expressed in terms of the effective collision strength $\mathrm{T}_{i j}\left(\mathrm{~T}_{\mathrm{e}}\right)$ ( (see Appendix), where

$$
T_{i j}\left(T_{e}\right)=\int_{0}^{\infty} \Omega(i, j) \exp \left(-\varepsilon_{i} / k T_{e}\right) d\left(\varepsilon_{i} / k T_{e}\right),
$$

$\varepsilon_{i}$ is the energy of the electron with respect to the $i$ th level, $k$ is the Boltzmann constant and $\Omega(i, j)$ is the collision strength. For the low temperatures found in nebulae the cross section ( $i . e . \Omega(i, j)$ ) must be calculated at low energies $\left(\varepsilon_{i} \lesssim 1\right.$ Ryd) where it is dominated by threshold effects such as resonances and the opening of new reaction channels. To be able to reproduce these effects detailed descriptions of the target 
ion and the collision process are needed. Moreover, for light ions relativistic effects are usually neglected and LS coupling assumed; cross sections between fine-structure levels are then calculated by algebraic transformations of the reactance matrix ${ }^{24}$.

The total wave function of the N-electron target ion + incoming electron is expanded in terms of the target eigenfunctions by the closecoupling (CC) expansion

$$
\Psi(L S)=\sum_{i} A_{b} x_{i} \theta_{i}+\sum_{j} c_{j} \Phi_{j} \cdot
$$

Each term in the first summation gives rise to an interaction channel; $X_{i}$ are the target eigenfunctions, $\theta_{i}$ the incident-electron functions and $A_{6}$ is an antisymmetrising operator. $\Phi_{j}$ take the form of bound-state configurations for the $(\mathrm{N}+1)$-electron system and account for short-range correlations effects. The variational principle leads to a set of coupled integro-differential equations of the general form

$$
\left\{\frac{d^{2}}{d r^{2}}-\frac{\ell_{i}\left(l_{i}+1\right)}{r^{2}}+\frac{2 z}{r}+\varepsilon_{i}\right\} F_{i}(r)+\sum_{i} W_{i i^{\prime}} F_{i}(r)=0
$$

where $F_{i}(r)$ is the ith channel electron radial functions. The interchannel coupling potentials $W_{i i}$ ' give rise to the threshold effects mentioned above, and sufficient channels must be included in the CC expansion to account for the effects present in the region of interest. In earlier methods such as the Coulomb-Born and distorted wave the radial functions $\mathrm{F}_{i}(\mathrm{r})$ were calculated neglecting this coupling, and in the exact resonance approximation ${ }^{26}$ the important quadrupole $p$-wave interactions were introduce perturbatively. At present the coupled equations are solved numerically by different methods such as the Linear Algebraic (IIPACT) ${ }^{27}$, the R-mat$\mathrm{rix}^{28}$ and the Non-iterative Integral Equation (NIEM) ${ }^{29}$ methods. The Linear Algebraic method, in particular, can also be used to calculate boundstate energies for the $(\mathrm{N}+1)$-electron system which leads to an indirect estimate of the accuracy of the cross sections.

Advances in this field have been boosted by the introduction of supercomputers. It is now possible to study ions of the first and second rows of the periodic table with accurate CI target wave functions and sufficient target states in the CC expansion to ensure convergence. There have also been attempts to treat the ions of $\mathrm{Fe}$ with some consistency ${ }^{14}$. The carbon and silicon sequences have been studied extensively; in figure 1 we plot $z^{2} T_{i j}(10000)$ (which tends to a constant limit as $z \rightarrow \infty$ ) as a function of $z$, where $z$ is the effective charge of the ion, for the $3_{P}-1_{D}$ and $1_{D}-1_{S}$ forbidden transitions of the $n p^{2}$ configurations. It can be seen that the older results obtained with the exact resonance and distorted wave approximations can show large differences from recent close-coupling results. 

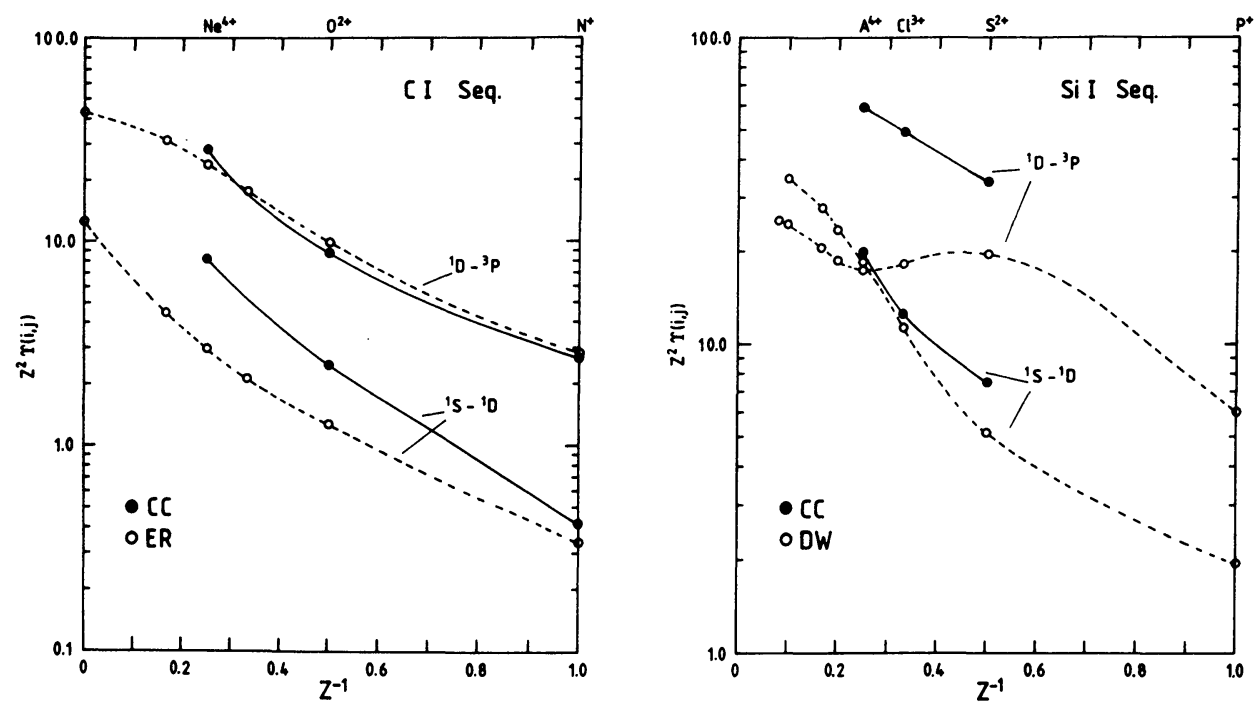

FIGURE 1. $\mathrm{z}^{2} \mathrm{~T}(10000)$ as a function of $\mathrm{z}$ (the effective charge of the ion) for the ${ }^{3} \mathrm{P}-1 \mathrm{D}$ and ${ }^{1} \mathrm{D}-{ }^{1} \mathrm{~S}$ forbidden transitions of the carbon and silicon sequences. CC - recent close-coupling results; ER - exact resonance approximation (ref.26); DW - distorted wave results (ref.35).

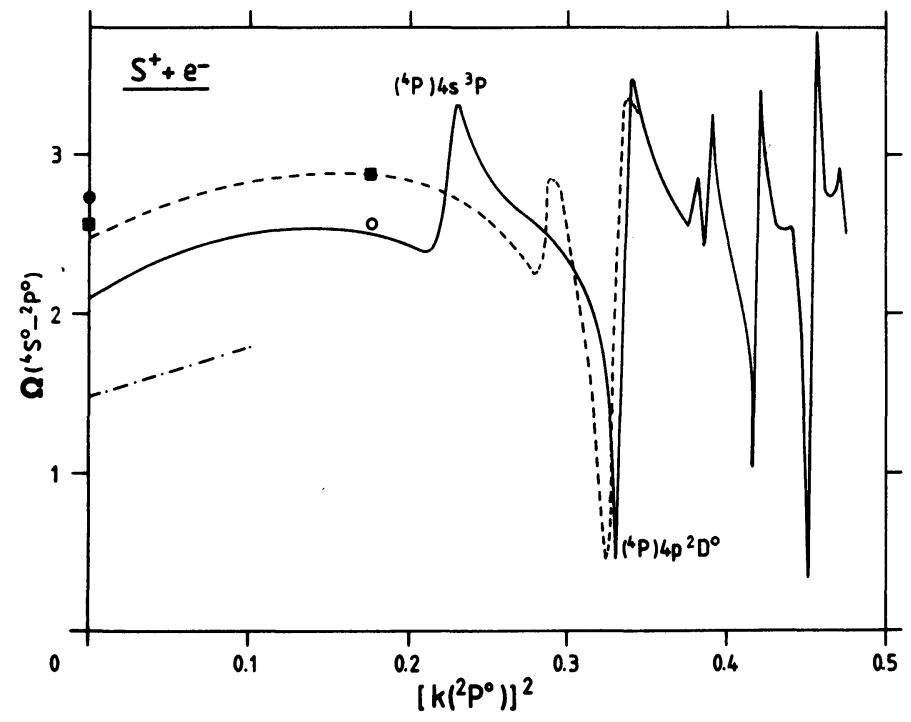

FIGURE 2. Total collision strength for the ${ }^{4} \mathrm{~S}^{0}-{ }^{2} \mathrm{P}^{0}$ transition of $\mathrm{S}^{+}$. Work by Pradhan ${ }^{36}$ in $3 C C+C I$ (filled circles) and DW (filled squares) approximations; DW results by Krueger and Czyzak ${ }^{35}$ (dot-dashed curve); recent results by Mendoza ${ }^{34}$ in a $6 C C+C I$ approximation using the $R$-matrix method (solid curve) and Linear Algebraic method (dashed curve). 
For some cases, such as the forbidden transitions of $0^{2+}$ (ref. 30 , 31), $\mathrm{Ne}^{4+}$ (ref. 32, 33) and $\mathrm{S}^{+}$(ref. 34), there are comparisons using different close-coupling methods which gives a more realistic indication of the accuracy of the collision rates. In general the agreement is very good, but some transitions show discrepancies greater than the error margin assigned by the authors $(\leqslant 10 \%)$. This is mainly due to shifts in the resonance positions as illustrated in figure 2 for the ${ }^{4} S^{\circ}-{ }^{2} P^{0}$ transition of $\mathrm{S}^{+}$. Mendoza ${ }^{34}$ has carried out comparative calculations for this transition using the Linear Algebraic and R-matrix methods. Although the same approximation was used in both calculations $(6 C C+C I)$ the target orbitals employed by these two packages are calculated by different methods: the former uses orbitals calculated in a Thomas-Fermi statistical model potential whereas the latter uses Hartree-Fock orbitals. The earlier results by Krueger and Czyzak ${ }^{35}$ and Pradhan ${ }^{36}$ are also shown.

In recent years there has also been progress in the relativistic treatment of the scattering problem. For intermediate-weight atoms the relativistic effects can be included by using the Breit-Pauli Hamiltonian; Scott and Burke ${ }^{7}$ have combined this approach with the R-matrix method to calculate excitation cross sections for Fe XXIII finding large discrepancies with the non-relativistic case. For heavier ions it becomes necessary to base the scattering problem on the Dirac equation; Norrington and Grant $^{38}$ have included the Dirac Hamiltonian in the R-matrix formalism and tested their code with the electron scattering from $\mathrm{Ne}^{+}$. They find excellent agreement with previous non-relativistic calculations in support of the approximation mentioned above.

The most outstanding experimental work on electron impact excitation of multiply-ionized ions is that by Dunn and co-workers on the resonance transition of the $\mathrm{Li}, \mathrm{Na}$ and $\mathrm{K}$ isoelectronic sequences using the crossed beams technique $39,40,41$. They obtain absolute cross sections for $\mathrm{C}^{3+}$ and $\mathrm{N}^{4^{+}}$which agree with close-coupling calculations to better than $10 \%$. This method has been refined recently to pick up the resonance structure found in the theoretical excitation cross section of $\mathrm{Hg}^{+}$(ref. 42), and preliminary results show satisfying agreement.

\section{PHOTOIONIZATION CROSS SECTIONS}

Experiments show that in most cases the photoionization continuum of light atoms is dominated by special features such as resonances, Cooper minima and delayed maxima. A similar situation is found by theory for the lowly-ionized species.

At present there are two tendencies in the calculation of photoionization cross sections for the large number of atoms and ions needed in astrophysics. On the one hand, there are detailed calculations which include electron correlation effects and aim at bringing out the complicated resonance structure and features of the cross section. Methods such as the close-coupling (described in the previous section) and ManyBody Perturbation Theory ${ }^{4}$ are used. On the other hand, there are calcu- 


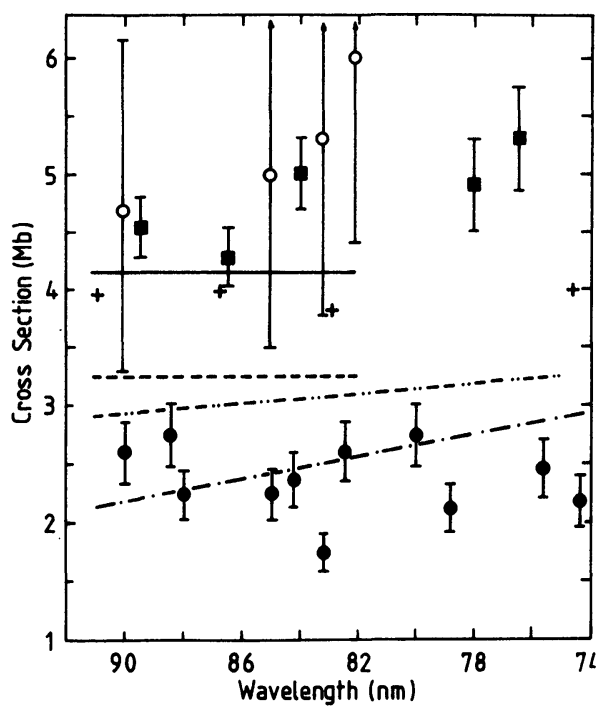

FIGURE 3. Present state of knowledge of the photoionization cross section of the ground state of $0^{\circ}$ in the threshold region. Experiments by Cairns and Samson ${ }^{4}$ (open circles); Comes et a1. ${ }^{8}$ (filled circles); Koh1 et a1.9. (filled squares). Theoretical results by Henry ${ }^{\circ}$ in the length (dot-dashdotted curve) and velocity (dot-dashed curve) formulations; close-coupling results by Taylor and Burke 51 in the length (solid curve) and velocity (dashed curve) formulations; close-coupling results by Pradhan and Saraph ${ }^{5}$ in the length formulation (crosses). Figure originally by Kohl et a1.

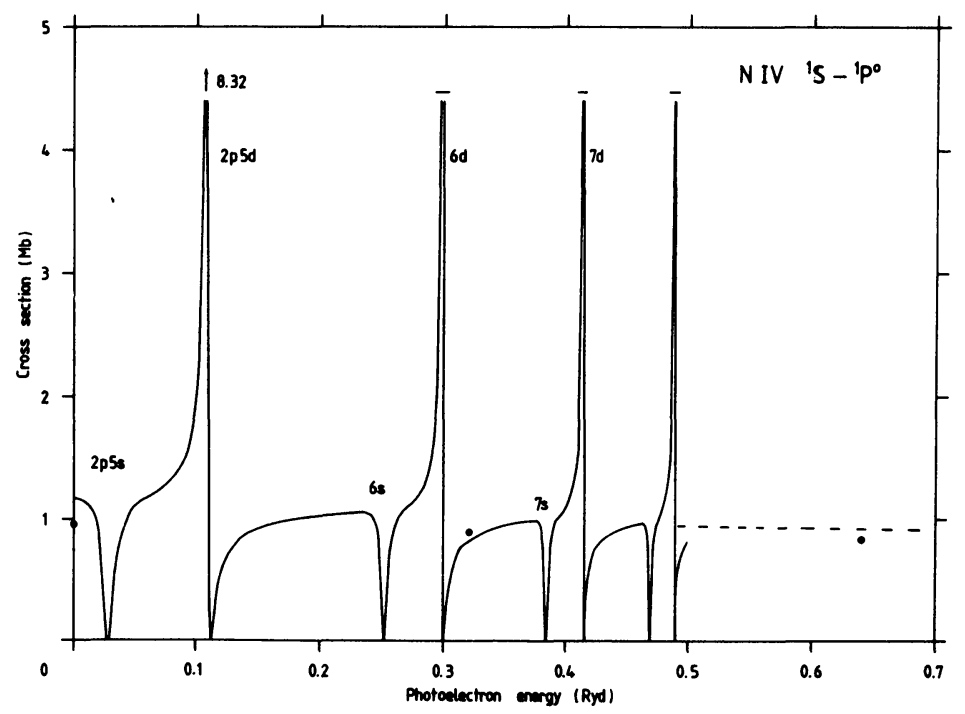

FIGURE 4. Photoionization cross section of the ground state of $\mathrm{N}^{3+}$. Solid curve - close-coupling results by Butler et al. (to be published); dashed

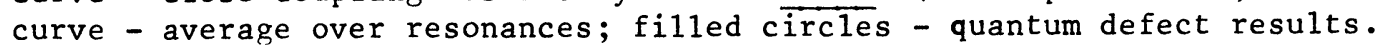


lations based on central potential approximations 44945 or semi-empirical methods such as the one-channel Quantum Defect Theory ${ }^{46}$ which only attempt to obtain the general behaviour of the cross section over a broad energy range, and these results are widely used in astrophysics.

In figure 3 we summarize the present state of knowledge of the photoionization cross section of the ground state of $0^{\circ}$ in the threshold region. It has taken almost a decade for experiment and theory to converge to a common result. The central potential calculation of Reilman and Manson ${ }^{44}$ (not shown) grossly over-estimates the cross section in this region. In figure 4 the photoionization cross section of the ground state of $\mathrm{N}^{3+}$ is shown. It can be seen that correlation effects (resonances) are still conspicuous even for a fairly stripped ion, but the background of the cross section is obtained satisfactorily by the Quantum Defect method. Reilman and Manson ${ }^{44}$ also obtain the background accurately in this region.

There is good agreement between theory and experiment for the rare gases, $\mathrm{C}^{\circ}, \mathrm{N}^{\circ}, 0^{\circ}$ and $\mathrm{Al} \mathrm{l}^{\circ}$, but there are long-standing discrepancies for the alkalis. For ions there are no absolute experimental results, but it is possible for some numerical methods, such as the Linear Algebraic, to compute f-values at the same time. These can be compared with experiment to obtain an indirect estimate of the absolute value of the cross section.

There is also recent work on the relativistic effects of the photoionization cross section. Taylor and Scott ${ }^{53}$ have calculated the resonance structure between the $\mathrm{J}=3 / 2$ and $1 / 2$ leve 1 s of the $\mathrm{A}^{+}$ground state obtaining good agreement with experiment. Chang ${ }^{54}$ has included the Dirac Hamiltonian in the R-matrix formalism and calculated the photoionization cross section of the ground state of $\mathrm{Ne}^{\circ}$. He finds close agreement with previous non-relativistic results.

\section{FUTURE WORK}

There remains a lot of work to be done in this interesting field. We can summarize the priority areas as follows.

(i) Radiative and collision rates for transitions to the $n=3$ states of $\mathrm{He}^{\mathrm{O}}$.

(ii) Fine-structure collision rates for the intercombination lines of ions of the $B$ isoelectronic sequence.

(iii) Transition probabilities and fine-structure collision rates for ions of the $\mathrm{Mg}$ and $\mathrm{Al}$ sequences.

(iv) Comparative CI calculations of transition probabilities for forbidden lines of the np ${ }^{q}$ configurations, particularly of neutrals, using different types of orbitals. At the moment there is only a detailed comparison for $0^{2+}$ (ref. 55).

(v) Fine-structure collision rates for the IR forbidden lines of ions of the first and second row.

(vi) Collision rates for ions of the second tow such as Si, Cl and A. (vii) Radiative and collision rates for the larger ions. 
(viii) Detailed photoionization cross sections of atoms and ions, particularly from excited states and inner shells. Presentation of the data is also an important factor here.

\section{ACKNOWLEDGEMENTS}

I am indebted to Professor MJ Seaton for his constant encouragement throughout the course of this work and to Drs. KM Aggarwal (Belfast), MA Hayes (UCL) and $\mathrm{K}$ Giles for allowing me to include some of their results in the compilation before publication. I am grateful to $\mathrm{Dr}$. KA Berrington (Belfast) for assistance with the Daresbury Laboratory Data Bank. Finally, I acknowledge enjoyable and fruitful collaboration with Drs. CJ Zeippen (Meudon) and $\mathrm{K}$ Butler (UCL).

\section{REFERENCES}

1. Jones M, 1970, J.Phys.B, 3, 1571; 1971, 4, 1422 .

2. Zeippen CJ, Seaton MJ and Morton DC, 1977, Mon.Not.R.astr.Soc., 181, 527.

3. Garstang RH, 1968, "Planetary Nebulae", eds. Osterbrock \& O'De1l, (Dordrecht; Reide1), p.143.

4. Czyzak SJ and Krueger TK, 1963, Mon.Not.R.astr.Soc., 126, 177; $1965,129,103$.

5. McKim-Malvilie J and Berger RA, 1965, Planet.Space Sci., 13, 1131.

6. Laugh 1 in C and Victor GA, 1974, Astrophys.J., 192, 551; 1979, 234, 407.

7. Eissner $\mathrm{W}$ and Zeippen CJ, 1981, J.Phys.B, 14, 2125 .

8. Drake GWF, 1971, Phys.Rev.A, 3, 908.

9. Kaler JB, Aller LH, Czyzak SJ and Epps HW, 1976, Astrophys.J.Suppl.Ser., 31,163 .

10. Dopita MA, Mason DJ and Robb WD, 1976, Astrophys.J., 207, 102 .

11. Zeippen CJ, 1982, Mon.Not.R.astr.Soc., 198, 111.

12. Mendoza C and Zeippen CJ, 1982, Mon.Not.R.astr.Soc., 198, 127; 199, 1025; in press.

13. Nussbaumer $\mathrm{H}$ and Rusca C, 1979, Astron.Astrophys., 72, 129.

14. Nussbaumer $\mathrm{H}$ and Storey PJ, 1978, Astron.Astrophys., 70, 37; $1980,89,308 ; 1982$, in press.

15. Glass $R$ and Hibbert A, 1978, J.PhysB, 11, 2413.

16. Nussbaumer $\mathrm{H}$ and Storey PJ, 1978, Astron.Astrophys., 64, 139; 1979, 74, 244 .

17. Cowan RD,Hobbs LM and York DG, 1982, Astrophys.J., 257, 373.

18. Hata J and Grant IP, 1981, J.Phys.B, 14, 2111.

19. Woodworth JR and Moos HW, 1975, Phys.Rev.A, 12, 2455.

20. Cheng KT, Kim YK and Desclaux JP, 1979, At.Dat.Nuc1.Dat.Tahles, 24, 111.

21. Corney A and Williams OM, 1972, J.Phys.B, ㅁ, 686.

22. Nightingale MPS, 1982. Ph.D. thesis, University of London.

23. Mendoza C, 1981, Rev.Mex.Astron.Astrofis., 6, 285.

24. Saraph HE, 1972, Comput.Phys.Commun., $3,25 \overline{6}$.

25. Seaton MJ, 1975, Adv.Atom.Molec.Phys., 11, 83.

26. Saraph HE, Seaton MJ and Shemming J, 1969, Phil.Trans.R.Soc.A, 264, 77. 
27. Seaton MJ, 1974, J.Phys.B, 7, 1817.

28. Burke PG, Hibbert $A$ and Rob 5 WD, 1971, J.Phys.B, 4, 153.

29. Smith ER and Henry RJW, 1973, Phys.Rev.A, 7, 1585.

30. Eissner $W$ and Seaton MJ, 1974, J.Phys.B, 7, 2533.

31. Baluja KL, Burke PG and Kingston AE, 1981, J.Phys.B, 14, 119.

32. Giles K, 1979, Mon.Not.R.astr.Soc., 187, 49P.

33. Baluja KL, Burke PG and Kingston AE, 1980, J.Phys.B, 13, 4675.

34. Mendoza C, 1982, to be published.

35. Krueger TK and Czyzak SJ, 1970, Proc.R.Soc.Lond.A, 318, 531.

36. Pradhan AK, 1976, Mon.Not.R.astr.Soc., 177, 31 .

37. Scott NS and Burke PG, 1980, J.Phys.B, $13,4299$.

38. Norrington PH and Grant IP, 1981, J.Phys.B, 14, L261.

39. Taylor PO, Gregory D, Dunn GH, Phaneuf RA and Crandal1 DH, 1977, Phys. Rev.Lett., 39, 1256.

40. Gregory D, Dunn GH, Phaneuf RA and Crandal1 DH, 1979, Phys.Rev.A, 20,410 .

41. Tay1or PO and Dunn GH, 1973, Phys.Rev.A, 8, 2304.

42. Mendoza C, 1981, J. Phys.B, 14, 2465.

43. Kelly HP, 1964, Phys.Rev, 136, B896.

44. Reilman RF and Manson ST, 1979, Astrophys.J.Supp1.Ser., 40, 815 ;

$1981,46,115$.

45. Hofsaess $\overline{\mathrm{D}}, 1979$, At.Dat.Nuc1.Dat.Tables, 24, 285.

46. Peach G, 1967, Mem.R.astr.Soc., 71, 13.

47. Cairns RB and Samson JAR, 1965, Phys.Rev, 139, A1403.

48. Comes FJ, Speier F and Elzer A, 1968, Z. Naturforsch, 23a, 125.

49. Koh1 JL, Lafyatis GP, Palenius HP and Parkinson WH, 1978, Phys.Rev.A,

$18,571$.

50. Henry RJW, 1967, Planet.Space Sci., 1967, 15, 1747.

51. Taylor KT and Burke PG, 1976, J.Phys.B, 9, L353.

52. Pradhan AK and Saraph HE, 1977, J.Phys.B, 10, 3365.

53. Taylor KT and Scott NS, 1981, J.Phys.B, 14, L237.

54. Chang JJ, 1977, J.Phys.B, 10, 3195.

55. Baluja KL and Doyle JG, 1981, J.Phys.B, 14, L11. 


\section{APPENDIX}

COMPILATION OF TRANSITION PROBABILITIES, ELECTRON EXCITATION RATE COEFFICIENTS AND PHOTOIONIZATION CROSS SECTIONS

We include in this section a selected and critically evaluated compilation of transition probabilities, electron excitation rate coefficients and photoionization cross sections for use in the study of planetary nebulae. We have attempted to present the data in a clear, practical and self-explanatory manner, but find it necessary to discuss briefly the general arrangements of the tables.

\section{INDICES}

Table 1 is an index of the ions and transitions for which A-values and electron excitation rate coefficients are included in this compilation. It also contains the numbers of the relevant tables (tables 2 9 ), the methods used, estimates of accuracy and the reference sources (referenced at the end of the Appendix). Similarly, table 10 contains a selected bibliography of photoionization cross sections; for each ion, the initial stages for which cross sections have been obtained, the states of the final ion, the method, accuracy and the reference source are given.

\section{METHODS}

The following abbreviations are used:

CI: Configuration interaction method.

nCC: n-state close-coupling approximation.

IV: Matrix variational method.

ER: Exact resonance approximation.

DW: Distorted wave approximation.

CBII: Unitarised Coulomb-Born approximation.

MP: Polarization model potential calculations.

$\mathrm{CP}$ : Central potential calculations.

MBPT: Many-body perturbation theory.

TDHF : Time-dependent Hartree-Fock method.

SE: Semi-empirical calculations.

TABLES: Values obtained from NBS tables.

INT(EXT): Interpolated (Extrapolated).

COMP: Compilation of several methods.

EXPT: Experiment.

\section{ACCURACY}

The following scheme is used:

A: Uncertainties within $10 \%$

B : " " $20 \%$ 
C: Uncertainties within $30 \%$
D:

A + sign means "much better than". Accuracy ratings given in this work should only be treated as a rough guide as it is very difficult to critically evaluate these data due to the general lack of experimental results, theoretical comparisons and even error estimates provided by the authors themselves. Furthermore, it is not practical within the present context to give estimates of uncertainties for every transition within a multiplet or configuration, and in some cases they can be significantly different. For instance, for the $n s^{2}$ - nsnp transitions of the $B e$ and $\mathrm{Mg}$ sequences, it is the transition probability for the intercombination line ${ }^{1} \mathrm{~S}_{0}-{ }_{\mathrm{P}} \mathrm{O}$ that shows the greater uncertainties whereas the A-values for the other transitions are probably correct to $5 \%$; for the forbidden transitions within the $n p q$ configurations the accuracy of the $M I$ transition probabilities is appreciably greater than that of the E2 type; also the accuracy of the photoionization cress section of the ground state of an ion can differ from that of the excited states, and the error in the cross sections can also vary with the energy region particularly where resonances are present.

Tables 2 - 9 are arranged in isoelectronic sequences. For each transition they list: the observed energy level separation $\Delta E_{i j}\left(\mathrm{~cm}^{-1}\right)$, the transition probability $A_{j j}\left(\mathrm{sec}^{-1}\right)$, and the effective collision strength $T_{i j}\left(T_{e}\right)$ as a function of electron temperature. The $i$ th level always corresponds to the upper level unless $\Delta \mathrm{E}$ appears with a negative sign (the $A$ and $T$ values are always for the downward transition). The electron de-excitation rate coefficient, $q_{i j}$, can be obtained from the relation

$$
q_{i j}\left(T_{e}\right)=\frac{8.63 \times 10^{-6} T_{i j}\left(T_{e}\right)}{\omega_{i} T_{e}^{\frac{1}{2}}} \quad\left(\mathrm{~cm}^{3} \sec ^{-1}\right)
$$

where $\omega_{i}$ is the statistical weight of the $i$ th level and $T_{e}$ is the electron temperature in $\mathrm{O}_{\mathrm{K}}$. The excitation rate coefficient is given by

$$
q_{j i}=\left(\omega_{i} / \omega_{j}\right) q_{i j} \exp \left(-\Delta E_{i j} / k T_{e}\right)
$$

where $k$ is the Boltzmann constant $(1 / \mathrm{k}=1.43883 \mathrm{~cm} \mathrm{~K})$.

When only one value of $T$ is given it is assumed to be temperature independent to within the accuracy of the calculation. A value of the effective collision strength bracketed by arrows $(\leftarrow T \rightarrow$ ) corresponds to the value for the whole multiplet (LS coupling); in this case the $T^{\prime} s$ for the fine-structure transitions can be obtained from the ratios of 
the statistical weights of the multiplet levels. For the ${ }^{2} P_{J}^{0}-{ }^{4} P_{J}$ transition of the $\mathrm{B}$ and $\mathrm{Al}$ isoelectronic sequences both the total $T$ for the multiplet and that for each fine-structure transition are given, as in some cases they have been computed by different methods (eg $\mathrm{N}^{2+}$ ) or, as explained by the author (eg $0^{3+}$ ), the sum of the finestructure components does not add up to the total LS value given.

Finally, the notation $a \pm b$ signifies $a \times 10^{ \pm b}$.

NOTE: The author kindly requests users to quote the original sources whenever data from this compilation are referenced. 


\begin{tabular}{|c|c|c|c|c|c|c|c|c|}
\hline \multirow[t]{2}{*}{ ION } & \multirow[t]{2}{*}{ TRANSITION(S) } & \multirow[b]{2}{*}{ TABLE } & \multicolumn{3}{|c|}{$A_{I V}$} & \multicolumn{3}{|c|}{$\Upsilon_{I J}$} \\
\hline & & & METHOD & $A C C$ & SOURCE & ME THOD & $A C C$ & SOURCE \\
\hline $\mathrm{H}^{\circ}$ & $n=2$ & 2 & TABLES & A+ & 1 & cc & B+ & 120 \\
\hline $\mathrm{He}^{\circ}$ & $n=2$ & 2 & COMP & A & $1,2,3,4,5$ & $5 \mathrm{cc}$ & $\mathrm{C}_{+}$ & 6 \\
\hline$c^{\circ}$ & $2 p^{2}{ }^{\prime} s,{ }^{1} D,{ }^{3} p$ & 6 & CI & A & 7 & $\mathrm{CC}+\mathrm{CI}$ & c & 8 \\
\hline$c^{\circ}$ & $2 \varepsilon 2 p^{3} 5 s_{2}^{0}-2 s^{2} 2 p^{2}{ }^{3} p_{J}$ & 6 & CI & B & 39 & Mv & & 9 \\
\hline$c^{+}$ & $282 p^{2}{ }^{4} p_{J}-2 s^{2} 2 p^{2} p_{J}^{0}$, & 5 & CI & B+ & 10 & $8 \mathrm{CC}+\mathrm{CI}$ & B & 11 \\
\hline $\mathrm{c}^{+}$ & $2 s 2 p^{2} 4 p-$ & 5 & & & & $\mathrm{SCC}+\mathrm{CI}$ & B+ & 12 \\
\hline$c^{2+}$ & $282 \mathrm{P}{ }^{1} \mathrm{P}_{1}^{0},{ }^{3} \mathrm{P}_{\mathrm{J}}^{0}, 2 s^{2}{ }^{1} S_{0}$ & 4 & CI & $A$ & 13 & $6 C C+C I$ & $A$ & 14 \\
\hline$c^{3+}$ & $2 p^{2} P_{J}^{0}$ & 3 & TABLES & A+ & 1 & EXPT ; 5CC & $A^{+}$ & $15 ; 16$ \\
\hline $\mathrm{N}^{\circ}$ & $2 p^{32} p^{0}$ & 7 & CI & A & 17 & $8 C C+C I$ & A & 18 \\
\hline $\mathrm{N}^{\circ}$ & ${ }^{2} \mathrm{P}_{\mathrm{J}}^{0}-$ & 7 & CI & A & 17 & $\mathrm{cc}$ & c & 19 \\
\hline $\mathrm{N}^{+}$ & $2 p^{2} \mathrm{I} s, I_{D}$ & 6 & CI & A+ & 7 & $\mathrm{CC}+\mathrm{CI}$ & A & 20 \\
\hline $\mathrm{N}^{+}$ & $2 p^{2} 3 p$ & 6 & CI & A+ & 7 & ER & $\mathrm{c}$ & 21 \\
\hline $\mathrm{N}^{+}$ & $2 s 2 p^{3} 5 s_{2}^{0}-2 s^{2} 2 p^{2}{ }^{3} p_{J}$ & 6 & CI & B+ & 22 & $\mathrm{CCC}+\mathrm{CI}$ & B+ & 12 \\
\hline $\mathrm{N}^{2+}$ & $2 \approx 2 p^{2}{ }^{4} P_{J}-2 s^{2} 2 p^{2} P_{J}^{0}$, & 5 & CI & $\mathrm{B}+$ & 23 & DW & c & 23 \\
\hline $\mathrm{N}^{2+}$ & $282 p^{2}{ }^{4} p-2 q^{2} 2 p^{2} p^{0}$ & 5 & & & & $6 \mathrm{CC}+\mathrm{CI}$ & A & 24 \\
\hline $\mathrm{N}^{3+}$ & $2 \approx 2 \mathrm{p}{ }^{1} \mathrm{P}_{\mathrm{I}}^{0},{ }^{3} \mathrm{P}_{\mathrm{J}}^{0}, 2 \mathrm{~s}^{2}{ }^{1} \mathrm{~s}_{0}$ & 4 & CI & A & 25 & INT & B+ & \\
\hline $\mathrm{N}^{4+}$ & $2 \mathrm{p}^{2} \mathrm{P}_{\mathrm{J}}^{0}-2 \mathrm{~s}^{2} \mathrm{~s}_{\frac{1}{2}}$ & 3 & TABLES & $A^{+}$ & 1 & $2 \mathrm{cc}$ & A+ & 26,27 \\
\hline $0^{\circ}$ & $2 p^{4} \mathrm{I} s,{ }^{1} \mathrm{D},{ }^{3} p$ & 8 & CI & $\mathbf{A}$ & 28 & $6 C C+C I$ & A & 18 \\
\hline $0^{\circ}$ & $2 p^{4}{ }^{3} P_{J}-{ }^{3} P_{J}$. & 8 & CI & A & 28 & MN & B+ & 29 \\
\hline $0^{+}$ & $2 \mathrm{p}^{3}{ }^{2} \mathrm{P}_{\mathrm{J}}^{0},{ }^{2} \mathrm{D}_{\mathrm{J}}^{0},{ }^{4} \mathrm{~s}_{\frac{3}{2}}^{0}$ & 7 & CI & At & 17 & $5 \mathrm{CC}+\mathrm{CI}$ & A & 30 \\
\hline $0^{2+}$ & $2 \mathrm{~s}^{2} \mathrm{p}^{3}{ }^{5} \mathrm{~s}^{\circ}, 2 \mathrm{~s}^{2} 2 \mathrm{p}^{2}{ }^{1} \mathrm{~s},{ }^{1} \mathrm{D},{ }^{3} \mathrm{p}$ & 6 & CI & A+ & 31 & $12 \mathrm{CC}+\mathrm{CI}$ & A & 32 \\
\hline $0^{2+}$ & $2 \mathrm{p}^{2}{ }^{3} \mathrm{P}_{\mathrm{J}}-{ }^{3} \mathrm{p}_{\mathrm{J}}$ & 6 & CI & A+ & 31 & $12 \mathrm{CC}+\mathrm{CI}$ & A & 33 \\
\hline $0^{3+}$ & $2 \approx 2 p^{2}{ }^{4} P_{J}-2 s^{2} 2 p^{2} P_{J}^{0}$ & 5 & CI & B & 34 & $\mathrm{TCC}+\mathrm{CI}$ & A & 34 \\
\hline $0^{4+}$ & $2 \varepsilon 2 \mathrm{p}{ }^{1} \mathrm{P}_{\mathrm{I}}^{\mathrm{O}},{ }^{3} \mathrm{P}_{\mathrm{J}}^{0}, 2 \mathrm{~s}^{2} \mathrm{I}_{\mathrm{O}}$ & 4 & CI & A & 25 & $6 \mathrm{CC}+\mathrm{CI}$ & A & 14 \\
\hline $0^{5+}$ & $2 p^{2} P_{J}^{O}-2 s^{2} s_{\frac{1}{2}}$ & 3 & TABLES & $\mathrm{A}^{+}$ & 1 & CBII & A & 26 \\
\hline
\end{tabular}

TABLE 1. Index of transition probabilities, $A_{i j}$, and effective collision strengths, $T_{i j}$, for transitions in ions of interest in the atudy of planetary nebulae. For each ion the number of the relevant table (tables $2-9$ ), the method used, an estimate of the accuracy and the reference source (referenced at the end of the appendix) is given. 


\begin{tabular}{|c|c|c|c|c|c|c|c|c|}
\hline \multirow[t]{2}{*}{ ION } & \multirow[t]{2}{*}{ TRANSITION(S) } & \multirow[b]{2}{*}{ TABLE } & \multicolumn{3}{|c|}{$A_{1 / 2}$} & \multicolumn{3}{|c|}{$\Upsilon_{1 J}$} \\
\hline & & & METHOD & $A C C$ & SOURCE & METHOD & $A C C$ & SOURCE \\
\hline $\mathrm{Ne}^{+}$ & $2 p^{52}$ & 9 & cI & $A^{+}$ & 28 & $E R($ adj.) & $\bar{A}$ & 20 \\
\hline $\mathrm{Ne}^{2+}$ & $2 p^{4} 1$ & 8 & CI & $A^{+}$ & 28 & $4 \mathrm{CC}+\mathrm{CI}$ & A & 35 \\
\hline $\mathrm{Ne}^{2+}$ & $2 p^{4} 3$ & 8 & CI & $A+$ & 28 & ER & C & 21 \\
\hline $\mathrm{Ne}^{3+}$ & $2 \mathrm{p}^{3}{ }^{2} \mathrm{P}_{\mathrm{J}}^{0},{ }^{2} \mathrm{D}_{\mathrm{J}}^{0},{ }^{4} s_{\frac{3}{2}}^{0}$ & 7 & CI & $A^{+}$ & 17 & $9 \mathrm{CC}+\mathrm{CI}$ & A & 36 \\
\hline $\mathrm{Ne}^{4+}$ & $2 p^{2} I_{S}, I_{D}$ & 6 & CI & $A^{+}$ & 7 & $12 \mathrm{CC}+\mathrm{CI}$ & A & 37 \\
\hline $\mathrm{Ne}^{4+}$ & $2 \cdot 2 p^{3} 5 s_{2}^{0}-2 s^{2} 2 p^{2}{ }^{3} p_{J}$ & 6 & CI & $A$ & 39 & $12 \mathrm{CC}+\mathrm{CI}$ & A & 37 \\
\hline $\mathrm{Ne}^{4+}$ & $2 p^{23}$ & 6 & CI & A+ & 7 & ER & c & 21 \\
\hline $\mathrm{Ne}^{5+}$ & $2 s^{2} 2 p$ & 5 & TABLES & $A+$ & 1 & ER & c & 21 \\
\hline $\mathrm{Ne}^{6+}$ & $2.2 \mathrm{p}{ }^{1} \mathrm{P}_{\mathrm{I}}^{\circ},{ }^{3} \mathrm{P}_{\mathrm{J}}^{\mathrm{O}}, 2 \mathrm{~s}^{2} \mathrm{I}_{\mathrm{O}}$ & 4 & CI & $A$ & 25 & $6 \mathrm{CC}+\mathrm{CI}$ & A & 38 \\
\hline $\mathrm{Ne}^{2+}$ & $2 \mathrm{p}^{5}{ }^{2} \mathrm{P}_{\frac{1}{2}}^{0}-{ }^{2} \mathrm{P}_{\frac{1}{2}}^{0}$ & 9 & CI & A+ & 28 & ER & c & 21 \\
\hline $\mathrm{Na}^{3+}$ & $2 p^{4}{ }^{1} s_{0}, I_{D_{2}},{ }^{3} \mathrm{P}_{\mathrm{J}}$ & 8 & CI & $A^{+}$ & 28 & ER & $\mathrm{c}$ & 21 \\
\hline $\mathrm{Na}^{4+}$ & $2 \mathrm{p}^{3}{ }^{2} \mathrm{P}_{\mathrm{J}}^{0},{ }^{2} \mathrm{D}_{\mathrm{J}}^{0},{ }^{4} \mathrm{~s}_{3}^{0}$ & 7 & CI & A+ & 17 & ER & $c$ & 21 \\
\hline $\mathrm{Mg}^{\circ}$ & $383 \mathrm{P}^{3} \mathrm{P}_{\mathrm{I}}^{0},{ }^{3} \mathrm{P}_{\mathrm{J}}^{\mathrm{O}}, 3 \mathrm{~s}^{2}{ }^{1} \mathrm{~s}_{0}$ & 4 & $\mathrm{CI}, \mathrm{MP}$ & B & 39,40 & $\mathrm{DW}, \mathrm{CC}$ & & 41,42 \\
\hline $\mathrm{Mg}^{+}$ & $3 p{ }^{2} \mathrm{P}_{\mathrm{J}}^{0}-3 \varepsilon^{2} \mathrm{~s}_{\frac{1}{2}}$ & 3 & $\mathbb{M P}$ & A+ & 43 & $4 \mathrm{CC}$ & $\mathbf{A}$ & 44 \\
\hline $\mathrm{M}_{8}^{3+}$ & $2 p^{5}{ }^{2} P_{\frac{1}{2}}^{0}$ & 9 & CI & A+ & 28 & ER & c & 21 \\
\hline $\mathrm{Mg}^{4+}$ & $2 p^{4}$ & 8 & CI & A+ & 28 & ER & $\mathrm{c}$ & 21 \\
\hline $\mathrm{M}_{8}^{5+}$ & ${ }_{\mathrm{J}},{ }^{2} \mathrm{D}_{\mathrm{J}}^{\circ},{ }^{4} \mathrm{~s}_{\frac{1}{2}}^{0}$ & & CI & A+ & 17 & ER & c & 21 \\
\hline $\mathbf{S i}^{\circ}$ & $, \mathrm{D}_{2},{ }^{3} \mathrm{P}_{\mathrm{J}}$ & 6 & CI & $A$ & 45 & DW & & 46 \\
\hline $\mathrm{Si}^{+}$ & $383 p^{2}{ }^{4} p-3 \varepsilon^{2} 3 p{ }^{2} p^{0}$ & 5 & $\mathrm{CI}$ & B & 47 & $7 \mathrm{CC}+\mathrm{CI}$ & B & 48 \\
\hline $\mathrm{Si}^{2+}$ & 3.3P ${ }^{1} \mathrm{P}_{1}^{0},{ }^{3} \mathrm{P}_{\mathrm{J}}^{\mathrm{O}}, 3 \mathrm{~s}^{2}{ }^{1} \mathrm{~s}_{0}$ & 4 & $\mathrm{CI}, \mathrm{MP}$ & B & 39,40 & $12 \mathrm{CC}+\mathrm{CI}$ & B+ & 49 \\
\hline $\mathrm{Si}^{3+}$ & $3 \mathrm{p}{ }^{2} \mathrm{p}_{\mathrm{J}}^{\mathrm{O}}-3 \mathrm{e}^{2} \mathrm{~s}_{\frac{1}{2}}$ & 3 & $I C C+M P$ & A+ & 28 & DW & B & 26,50 \\
\hline $\mathrm{Si}^{5+}$ & $2 p^{5}{ }^{2} P_{\frac{1}{2}}^{0}-{ }^{2} P_{\frac{1}{2}}^{0}$ & 9 & CI & A+ & 28 & ER & c & 21 \\
\hline$s^{0}$ & $3 p^{4}{ }^{1} s_{0}, I_{D_{2}},{ }^{3} P_{J}$ & 8 & CI & $\mathbf{A}$ & 51 & & & \\
\hline$s^{+}$ & $3 \mathrm{p}^{3}{ }^{2} \mathrm{p}_{\mathrm{J}}^{\mathrm{O}},{ }^{2} \mathrm{D}_{\mathrm{J}}^{0},{ }^{4} \mathrm{~s}_{\frac{1}{2}}$ & 7 & CI & A+ & 52 & $6 C C+C I$ & A & 53 \\
\hline$s^{2+}$ & $3 p^{2} 1 s,{ }^{1}, 3^{3} p$ & 6 & CI & $A+$ & 45 & $12 \mathrm{CC}+\mathrm{CI}$ & B+ & 53 \\
\hline$s^{2+}$ & $3 \mathrm{p}^{2}{ }^{3} \mathrm{p}_{\mathrm{J}}-{ }^{3} \mathrm{p}_{\mathrm{J}}$ & 6 & CI & $A^{+}$ & 45 & $7 \mathrm{CC}+\mathrm{CI}$ & B+ & 53 \\
\hline$s^{3+}$ & $383 \mathrm{p}^{2}{ }^{4} \mathrm{P}_{\mathrm{J}}-3 \mathrm{~s}^{2} 3 \mathrm{p}{ }^{2} \mathrm{P}_{\mathrm{J}}^{0}$ & 5 & CI & B+ & 54 & $6 \mathrm{CC}+\mathrm{CI}$ & B+ & 54 \\
\hline$s^{4+}$ & $383 p p^{1}, 3_{p^{0}}, 3 \varepsilon^{2} 1_{S}$ & 4 & $C I, M P$ & B & 39,40 & $5 C C+C I$ & B+ & 56 \\
\hline$s^{4+}$ & $383 \mathrm{p}{ }^{3} \mathrm{P}_{\mathrm{J}}^{0}-{ }^{3} \mathrm{P}_{\mathrm{J}}^{0}$ & 4 & CI & At & 39 & $\mathrm{DW}(\mathrm{BXT})$ & & 55 \\
\hline$s^{5+}$ & $3 p^{2} P_{J}^{0}-3 \varepsilon^{2} s_{\frac{1}{2}}$ & 3 & $I C C+2 P$ & A+ & 28 & DW & B & 26,50 \\
\hline
\end{tabular}

TABLE 1. (continued) 


\begin{tabular}{|c|c|c|c|c|c|c|c|c|}
\hline \multirow[t]{2}{*}{ ION } & \multirow[t]{2}{*}{ TRANSITION(S) } & \multirow[b]{2}{*}{ TABLE } & \multicolumn{3}{|c|}{$A_{1 / 2}$} & \multicolumn{3}{|c|}{$\Upsilon_{1 \nu}$} \\
\hline & & & ME THOD & $A C C$ & SOURCE & METHOD & $A C C$ & SOURCE \\
\hline $\mathrm{Cl}^{\circ}$ & $3 p^{5}{ }^{2} p_{1}^{0}-{ }^{2} p_{\frac{1}{2}}^{0}$ & 9 & CI & $\Lambda+$ & 28 & & & \\
\hline $\mathrm{Cl}^{+}$ & $3 p^{4}{ }^{1} s_{0},{ }^{1} D_{2},{ }^{3} p_{J}$ & 8 & CI & $A+$ & 51 & DW & D & 57 \\
\hline $\mathrm{Cl}^{2+}$ & $3 \mathrm{p}^{3}{ }^{2} \mathrm{P}_{\mathrm{J}}^{0},{ }^{2} \mathrm{D}_{\mathrm{J}}^{0},{ }^{4} \mathrm{~s}_{\frac{3}{2}}^{0}$ & 7 & CI & $A+$ & 52 & DW & D & 57 \\
\hline $\mathrm{Cl}^{3+}$ & $3 p^{2} 1 s, 1 D,{ }^{3} p$ & 6 & CI & At & 45 & $12 \mathrm{CC}+\mathrm{CI}$ & B & 53 \\
\hline $\mathrm{Cl}^{3+}$ & $3 p^{2} 3_{P_{J}}$ & 6 & CI & $A^{+}$ & 45 & DW & D & 57 \\
\hline $\mathrm{Cl}^{4+}$ & $3 s^{2} 3 p^{2} P_{\frac{3}{2}}^{0}$ & 5 & CI & A+ & 28 & DW & D & 57 \\
\hline$A^{+}$ & $3 p^{5}{ }^{2} P_{\frac{1}{2}}^{0}-{ }^{2} p_{\frac{3}{2}}^{0}$ & 9 & CI & A+ & 28 & $\mathrm{DW}$ & D & 57 \\
\hline $\mathrm{A}^{2+}$ & $3 p^{4} I^{2} s_{0}, D_{2},{ }^{3} P_{J}$ & 8 & CI & A+ & 51 & DW & D & 57 \\
\hline$A^{3+}$ & $3 \mathrm{p}^{3}{ }^{2} \mathrm{P}_{\mathrm{J}}^{\mathrm{O}},{ }^{2} \mathrm{D}_{\mathrm{J}}^{0},{ }^{4} \mathrm{~s}_{\frac{3}{2}}^{0}$ & 7 & CI & $A^{+}$ & 52 & DW & D & 57 \\
\hline$A^{4+}$ & $3 p^{2}{ }^{\prime} s,{ }^{1} D,{ }^{3} p$ & 6 & CI & A+ & 45 & $12 \mathrm{CC}+\mathrm{CI}$ & B & 53 \\
\hline$A^{4+}$ & $3 \mathrm{p}^{2}{ }^{3} \mathrm{p}_{\mathrm{J}}-{ }^{3} \mathrm{p}_{\mathrm{J}}$. & 6 & CI & $A+$ & 45 & DW & D & 57 \\
\hline$A^{5+}$ & $3 s^{2} 3 p{ }^{2} \mathrm{P}_{\frac{2}{3}}^{0}-{ }^{2} \mathrm{P}_{\frac{1}{2}}^{0}$ & 5 & CI & $A^{+}$ & 28 & DW & D & 57 \\
\hline$k^{2+}$ & $3 p^{5} 2 p_{1}^{0}-{ }^{2} p_{\frac{3}{2}}^{0}$ & 9 & CI & $\mathrm{A}^{+}$ & 28 & DW & D & 57 \\
\hline $\mathrm{k}^{3+}$ & $3 p^{4} I^{\prime} s_{0},{ }^{1} D_{2}, 3^{3} P_{J}$ & 8 & CI & $\mathrm{A}^{+}$ & 51 & DW & D & 57 \\
\hline$k^{4+}$ & $3 \mathrm{p}^{3}{ }^{2} \mathrm{P}_{\mathrm{J}}^{\mathrm{O}},{ }^{2} \mathrm{D}_{\mathrm{J}}^{0},{ }^{4} \mathrm{~s}_{\frac{3}{2}}^{0}$ & 7 & CI & $A^{+}$ & 52 & DW & D & 57 \\
\hline $\mathrm{Ca}^{+}$ & $4 p^{2} P_{J}^{0}-4 s^{2} S_{\frac{1}{2}}$ & 3 & $M P$ & A & 43 & EXPT & A & 26,58 \\
\hline $\mathrm{Ca}^{3+}$ & $3 p^{5}{ }^{2} P_{\frac{1}{2}}^{0}-{ }^{2} P_{\frac{2}{2}}^{0}$ & 9 & CI & A+ & 28 & DW & D & 57 \\
\hline $\mathrm{Ca}^{4+}$ & $3 p^{4}{ }^{1} s_{0},{ }^{1} D_{2},{ }^{3} p_{J}$ & 8 & CI & $A+$ & 51 & DW & D & 57 \\
\hline $\mathrm{Fe}^{\circ}$ & Forbidden transitions & & CI & & 59 & & & \\
\hline $\mathrm{Fe}^{+}$ & Forbidden transitions & & CI & D & 60 & $4 \mathrm{CC}+\mathrm{CI}$ & D & 60 \\
\hline $\mathrm{Fe}^{2+}$ & Forbidden transitions & & SE & & 61 & $5 \mathrm{CC}$ & & 62 \\
\hline $\mathrm{Fe}^{3+}$ & Forbidden transitions & & SE & & 63,64 & & & \\
\hline $\mathrm{Fe}^{4+}$ & Forbidden transitions & & SE & & 61 & & & \\
\hline $\mathrm{Fe}^{5+}$ & Forbidden transitions & & CI & c & 65 & DW & c & 65 \\
\hline $\mathrm{Fe}^{6+}$ & Forbidden transitions & & CI & B & 66 & DW & c & 66 \\
\hline
\end{tabular}

TABLE 1. (continued) 

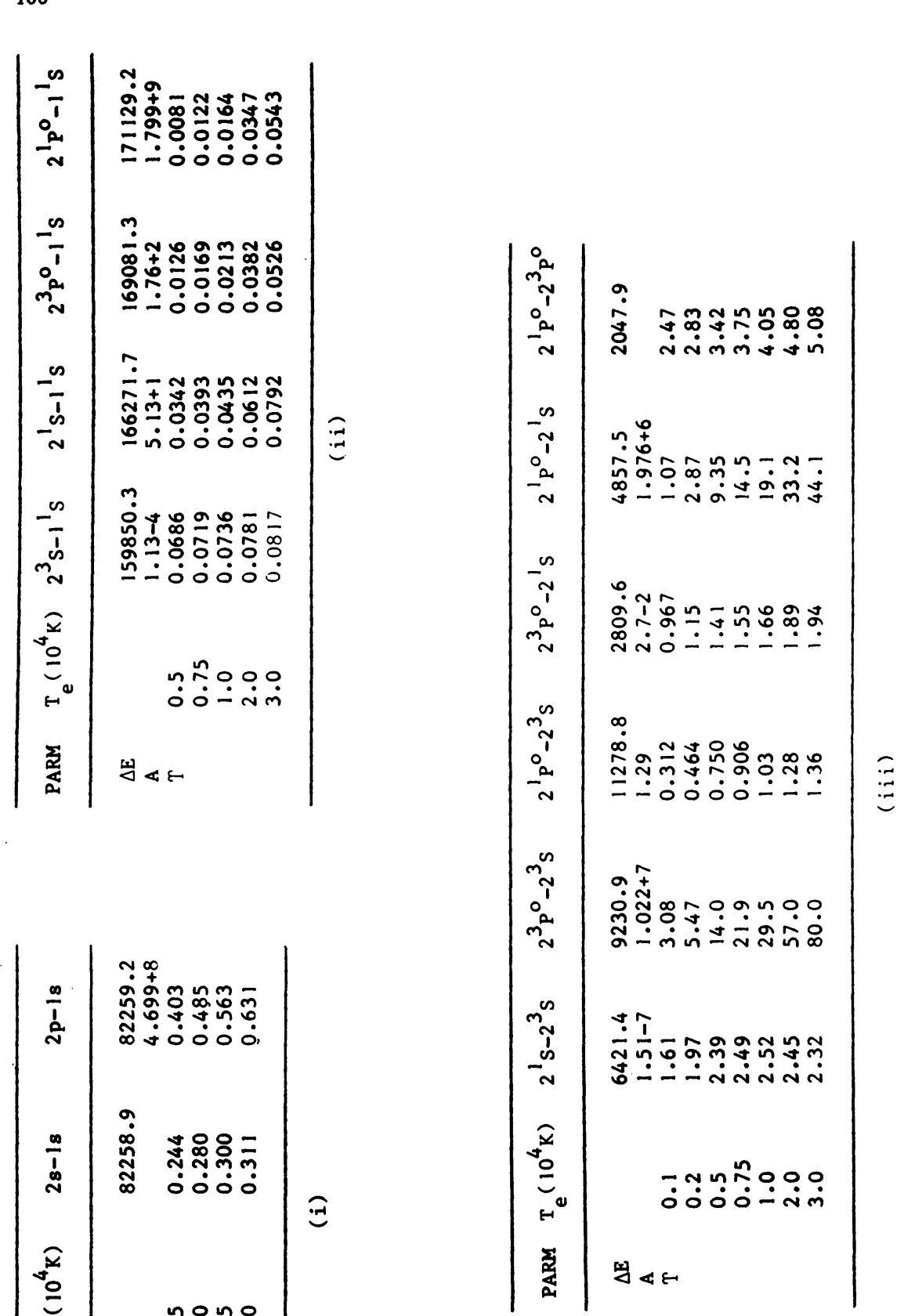

Ev

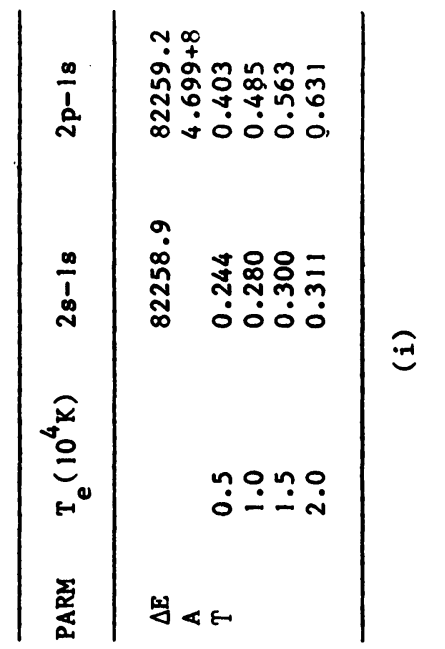

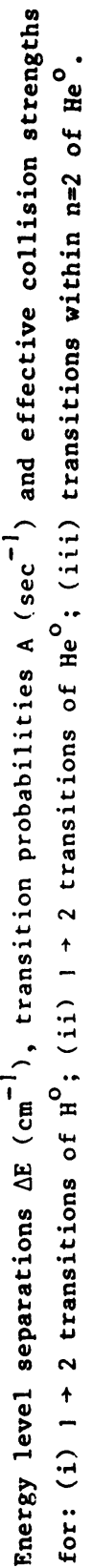

i 


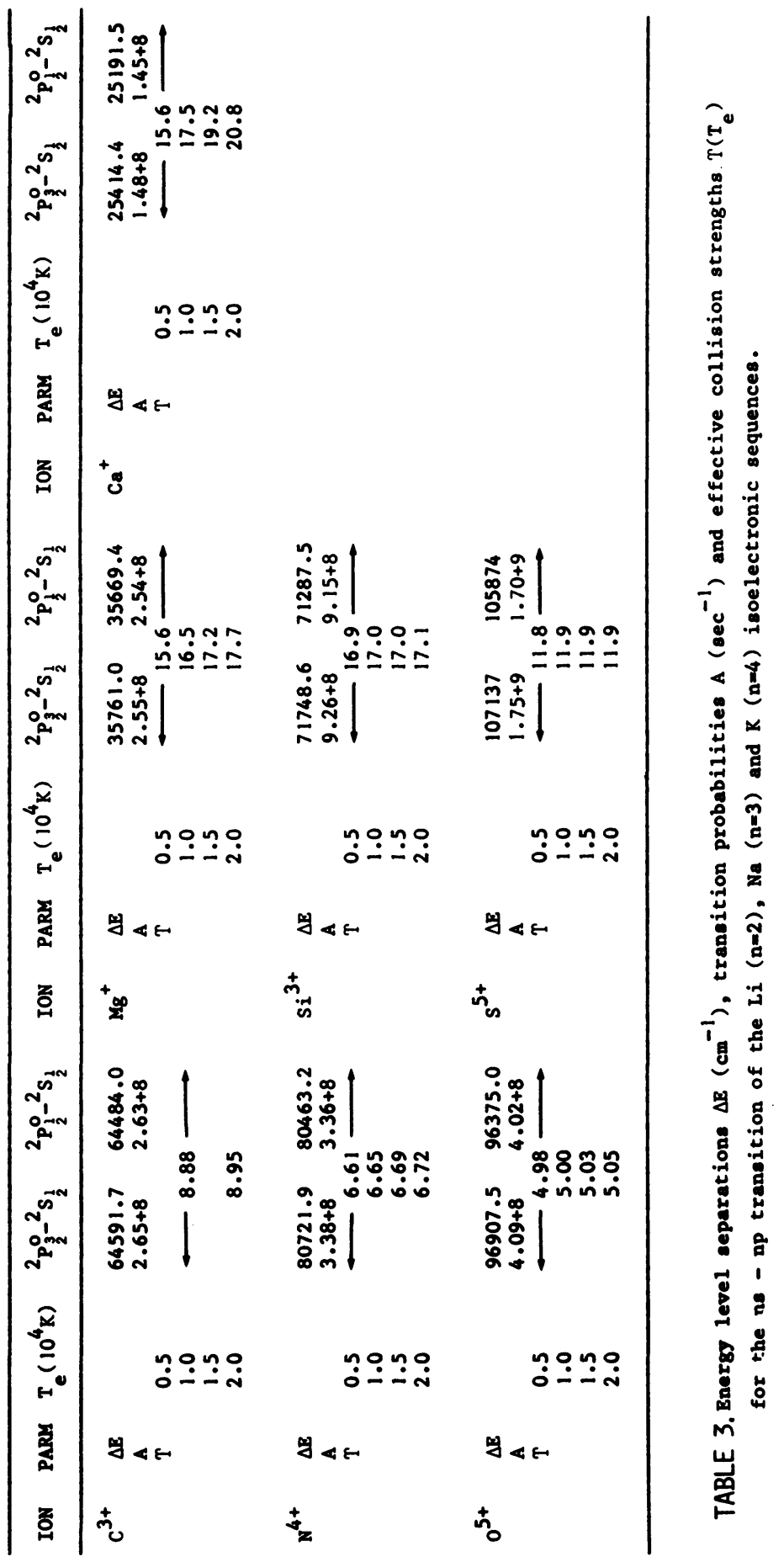




\begin{tabular}{|c|c|c|c|c|c|c|c|c|c|}
\hline ION & PARM & $\mathrm{T}_{\mathrm{e}}\left(10^{4} \mathrm{~K}\right)$ & ${ }^{3} \mathrm{P}_{2}^{\circ}-{ }^{1} \mathrm{~s}_{0}$ & ${ }^{3} \mathrm{P}_{1}^{0}-{ }^{1} \mathrm{~s}_{0}$ & ${ }^{3} \mathrm{p}_{0}^{\mathrm{o}}-{ }^{1} \mathrm{~s}_{0}$ & ${ }^{1} P_{1}^{0}-{ }^{1} S_{0}$ & ${ }^{3} \mathrm{P}_{1}^{0}-{ }^{3} \mathrm{P}_{0}^{0}$ & ${ }^{3} \mathrm{P}_{2}^{\circ}-{ }^{3} \mathrm{P}_{0}^{\circ}$ & ${ }^{3} \mathrm{P}_{2}{ }^{0}{ }^{3} \mathrm{P}_{1}{ }^{\circ}$ \\
\hline$c^{2+}$ & $\begin{array}{l}\Delta \mathrm{E} \\
\mathbf{A} \\
T\end{array}$ & $\begin{array}{l}0.5 \\
1.0 \\
1.5 \\
2.0\end{array}$ & $\begin{array}{l}52447.1 \\
5.19-3 \\
\end{array}$ & $\begin{array}{l}52390.8 \\
9.59+1 \\
1.12 \\
1.01 \\
0.990 \\
0.996\end{array}$ & 52367.1 & $\begin{array}{l}102352.0 \\
1.79+9 \\
3.85 \\
4.34 \\
4.56 \\
4.69\end{array}$ & $\begin{array}{l}23.7 \\
2.39-7 \\
0.848 \\
0.911 \\
0.975 \\
1.03\end{array}$ & $\begin{array}{l}80.1 \\
0.579 \\
0.677 \\
0.776 \\
0.867\end{array}$ & $\begin{array}{l}56.4 \\
2.41-6 \\
2.36 \\
2.66 \\
2.97 \\
3.23\end{array}$ \\
\hline $\mathrm{N}^{3+}$ & $\begin{array}{l}\Delta \mathrm{E} \\
\mathrm{A} \\
\mathrm{T}\end{array}$ & $\begin{array}{l}0.5 \\
1.0 \\
1.5 \\
2.0\end{array}$ & $\begin{array}{l}67416.3 \\
1.15-2 \\
\end{array}$ & $\begin{array}{l}67272.3 \\
5.77+2 \\
0.904 \\
0.852 \\
0.817 \\
0.798\end{array}$ & 67209.2 & $\begin{array}{l}130693.9 \\
2.38+9 \\
3.20 \\
3.46 \\
3.58 \\
3.65\end{array}$ & $\begin{array}{l}63 \cdot 1 \\
4.53-6\end{array}$ & 207.1 & $\begin{array}{l}144.0 \\
4.03-5\end{array}$ \\
\hline $0^{4+}$ & $\begin{array}{l}\Delta \mathrm{E} \\
\mathbf{A} \\
\mathrm{T}\end{array}$ & $\begin{array}{l}0.5 \\
1.0 \\
1.5 \\
2.0\end{array}$ & $\begin{array}{l}82385.3 \\
2.16-2 \\
\end{array}$ & $\begin{array}{l}82078.6 \\
2.25+3 \\
0.733 \\
0.721 \\
0.674 \\
0.639\end{array}$ & 81942.5 & $\begin{array}{l}158797.7 \\
2.92+9 \\
2.66 \\
2.76 \\
2.82 \\
2.85\end{array}$ & $\begin{array}{l}136.1 \\
4.54-5\end{array}$ & 442.8 & $\begin{array}{l}306.7 \\
3.89-4\end{array}$ \\
\hline $\mathrm{Ne}^{6+}$ & $\begin{array}{l}\Delta \mathrm{E} \\
\mathrm{A} \\
\mathrm{T}\end{array}$ & $\begin{array}{l}0.5 \\
1.0 \\
1.5 \\
2.0\end{array}$ & $\begin{array}{l}112711.5 \\
5.78-2 \\
\end{array}$ & $\begin{array}{l}111717 \\
1.98+4 \\
0.129 \\
0.172 \\
0.205 \\
0.228\end{array}$ & $\begin{array}{r}111264.9 \\
\longrightarrow\end{array}$ & $\begin{array}{l}214951.6 \\
4.08+9 \\
1.39 \\
1.56 \\
1.63 \\
1.66\end{array}$ & $\begin{array}{l}452 \\
1.69-3\end{array}$ & 1446.6 & $\begin{array}{l}995 \\
1.32-2\end{array}$ \\
\hline $\mathrm{Mg}^{\circ}$ & $\begin{array}{l}\Delta \mathrm{E} \\
\mathrm{A} \\
\mathrm{T}\end{array}$ & & $\begin{array}{l}21911.2 \\
4.13-4\end{array}$ & $\begin{array}{l}21870.5 \\
1.80+2\end{array}$ & 21850.4 & $\begin{array}{l}35051.3 \\
4.93+8\end{array}$ & $\begin{array}{l}20.1 \\
1.45-7\end{array}$ & $\begin{array}{l}60.8 \\
4.08-12\end{array}$ & $\begin{array}{l}40.7 \\
9.10-7\end{array}$ \\
\hline $\mathrm{Si}^{2+}$ & $\begin{array}{l}\Delta \mathrm{E} \\
\mathbf{A} \\
\mathrm{T}\end{array}$ & $\begin{array}{l}0.5 \\
1.0 \\
1.5 \\
2.0\end{array}$ & $\begin{array}{l}53115.0 \\
1.20-2 \\
\end{array}$ & $\begin{array}{l}52853.3 \\
1.26+4 \\
6.90 \\
5.43 \\
4.80 \\
4.41\end{array}$ & $\begin{array}{r}52724.7 \\
\longrightarrow\end{array}$ & $\begin{array}{l}82884.4 \\
2.60+9 \\
5.48 \\
5.82 \\
6.21 \\
6.54\end{array}$ & $\begin{array}{l}128.6 \\
3.82-5\end{array}$ & $\begin{array}{l}390.3 \\
3.20-9\end{array}$ & $\begin{array}{l}261.7 \\
2.42-4\end{array}$ \\
\hline$s^{4+}$ & $\begin{array}{l}\Delta \mathrm{E} \\
\mathrm{A} \\
\mathrm{T}\end{array}$ & $\begin{array}{l} \\
0.5 \\
1.0 \\
1.5 \\
2.0\end{array}$ & $\begin{array}{l}84155.2 \\
6.59-2 \\
\end{array}$ & $\begin{array}{l}83393.5 \\
1.26+5 \\
0.911 \\
0.910 \\
0.914 \\
0.905\end{array}$ & $\begin{array}{r}83024.0 \\
\longrightarrow\end{array}$ & $\begin{array}{l}127150.7 \\
5.13+9 \\
7.30 \\
7.30 \\
7.29 \\
7.27\end{array}$ & $\begin{array}{l}369.5 \\
9.07-4 \\
0.272\end{array}$ & $\begin{array}{l}1131.2 \\
1.63-7 \\
0.400\end{array}$ & $\begin{array}{l}761.7 \\
5.96-3 \\
1.24\end{array}$ \\
\hline
\end{tabular}

TABLE 4. Energy level separations $\Delta E\left(\mathrm{~cm}^{-1}\right)$, transition probabilities $A$ (sec ${ }^{-1}$ ) and effective collision strengths $T\left(T_{e}\right)$ for the $n s^{2}$ - nsnp transitions of the Be $(n=2)$ and $M g(n=3)$ isoelectronic sequences. 


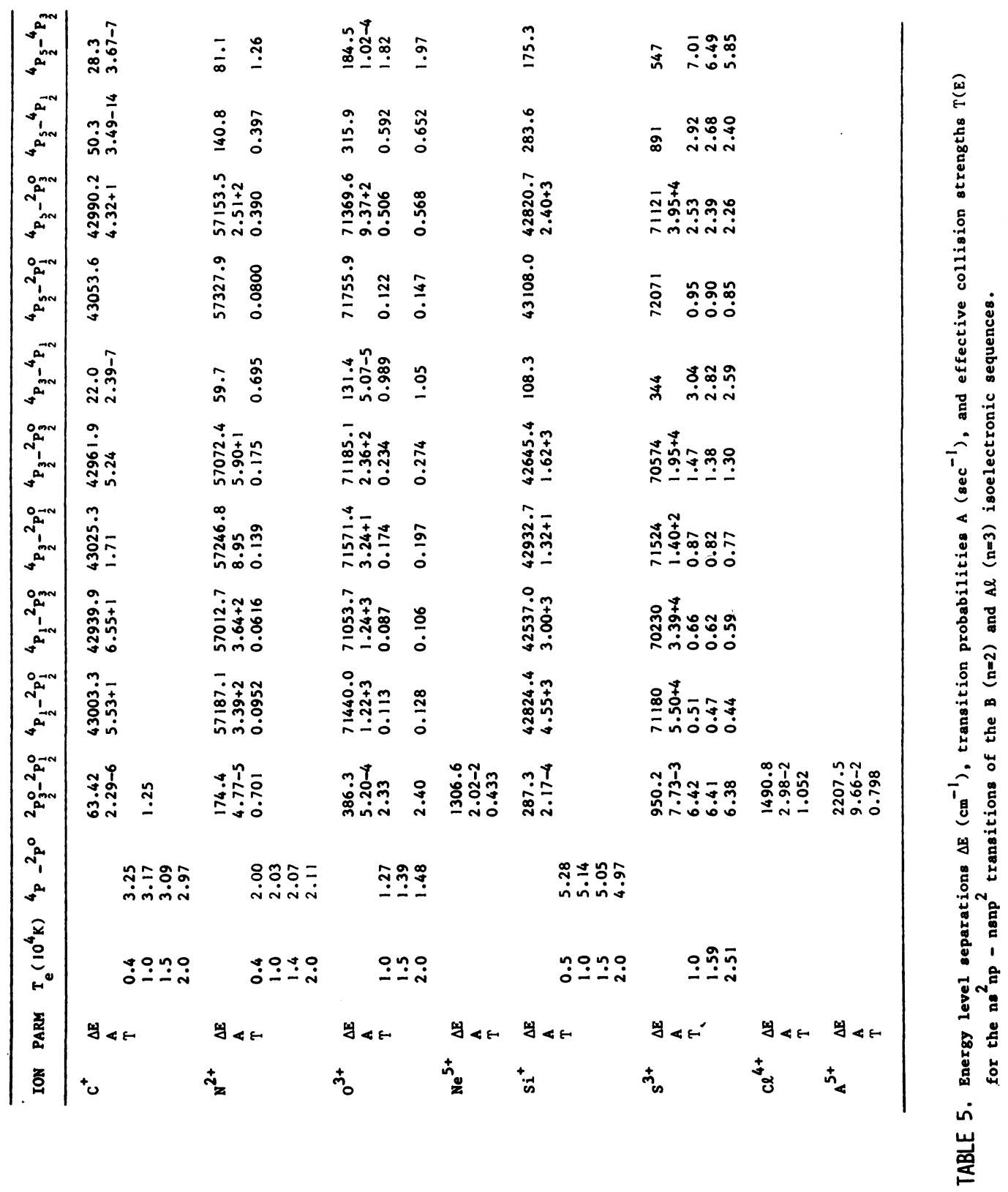




\begin{tabular}{|c|c|c|c|c|c|c|c|c|c|c|c|c|c|}
\hline ION & PARY & $x_{e}\left(10^{4} x\right)$ & ${ }^{D_{2}}{ }_{2}-{ }^{3} P_{0}$ & $\mathrm{I}_{\mathrm{D}_{2}-{ }^{3} \mathrm{P}_{1}}$ & ${ }^{I} D_{2}-{ }^{3} P_{2}$ & ${ }^{1} s_{0}={ }^{3} p$ & ${ }^{1} s_{0}-{ }^{3} P_{2}$ & ${ }^{\prime} s_{0}={ }^{\prime} D_{2}$ & ${ }^{3} P_{1}-{ }^{3} P_{0}$ & ${ }^{3} P_{2}-{ }^{3} P_{0}$ & ${ }^{3} P_{2}-{ }^{3} P_{1}$ & ${ }^{5} s_{2}^{0}-{ }^{3} P_{1}$ & ${ }_{s_{2}}^{0}-{ }^{3} P_{2}$ \\
\hline$c^{0}$ & $\hat{A B}$ & $\begin{array}{l}0.05 \\
0.1 \\
0.5 \\
1.0 \\
1.5 \\
2.0\end{array}$ & $\begin{array}{l}10192.6 \\
7.77-8 \\
\end{array}$ & $\begin{array}{l}10176.2 \\
8.21-5 \\
0.0625 \\
0.125 \\
0.603 \\
1.14 \\
1.60 \\
1.96\end{array}$ & $\begin{array}{l}10149.2 \\
2.44-4 \\
\end{array}$ & \begin{tabular}{r}
21631.6 \\
$2.71-3$ \\
\hdashline 0. \\
0
\end{tabular} & $\begin{array}{l}21604.6 \\
2.00-5 \\
0172- \\
0339 \\
149 \\
252 \\
320 \\
365\end{array}$ & $\begin{array}{l}11455.4 \\
5.28-1 \\
0.0620 \\
0.0877 \\
0.196 \\
0.277 \\
0.340 \\
0.392\end{array}$ & $\begin{array}{l}16.4 \\
7.93-8\end{array}$ & $\begin{array}{l}43.4 \\
1.71-14\end{array}$ & $\begin{array}{l}27.0 \\
2.65-7\end{array}$ & \multicolumn{2}{|c|}{$\begin{array}{cr}33718.8 & 33 \\
6.94 & 1 . \\
-0.150 \\
0.212 \\
0.475 \\
0.671 \\
0.822 \\
0.950\end{array}$} \\
\hline $\mathrm{s}^{+}$ & $\hat{\Delta B}$ & $\begin{array}{l}0.5 \\
1.0 \\
1.5 \\
2.0\end{array}$ & $\begin{array}{l}15316.2 \\
5.35-7 \\
\end{array}$ & $\begin{array}{l}15267.5 \\
1.01-3 \\
2.64 \\
2.68 \\
2.72 \\
2.73\end{array}$ & $\begin{array}{l}15185.4 \\
2.99-3 \\
\end{array}$ & $\begin{array}{r}32640.1 \\
3.38-2 \\
-0 \\
0\end{array}$ & $\begin{array}{l}32558.0 \\
1.51-4 \\
152 \longrightarrow \\
152 \\
59 \\
65\end{array}$ & $\begin{array}{l}17372.6 \\
1.12 \\
0.405 \\
0.411 \\
0.418 \\
0.425\end{array}$ & $\begin{array}{l}48.7 \\
2.08-6 \\
0.401\end{array}$ & $\begin{array}{l}130.8 \\
1.16-12 \\
0.279\end{array}$ & $\begin{array}{l}82.1 \\
7.46-6 \\
1.13\end{array}$ & $\begin{array}{r}46735.9 \\
4.8+1 \\
1 . \\
1 .\end{array}$ & 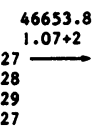 \\
\hline $0^{2+}$ & $\stackrel{\Delta E}{\hat{T}}$ & $\begin{array}{l}0.5 \\
1.0 \\
1.5 \\
2.0\end{array}$ & $\begin{array}{l}20273.3 \\
2.74-6 \\
\end{array}$ & $\begin{array}{l}20160.1 \\
6.74-3 \\
2.02 \\
2.17 \\
2.30 \\
2.39\end{array}$ & $\begin{array}{l}19967.1 \\
1.96-2 \\
\end{array}$ & $\begin{array}{r}43072.5 \\
2.23-1 \\
\\
0 \\
0 \\
0\end{array}$ & $\begin{array}{l}42879.5 \\
7.85-4 \\
48 \longrightarrow \\
76 \\
99 \\
14\end{array}$ & $\begin{array}{l}22912.4 \\
1.78 \\
0.516 \\
0.617 \\
0.638 \\
0.634\end{array}$ & $\begin{array}{l}113.2 \\
2.62-5 \\
0.517 \\
0.542 \\
0.553 \\
0.556\end{array}$ & $\begin{array}{l}306.2 \\
3.02-11 \\
0.257 \\
0.271 \\
0.281 \\
0.288\end{array}$ & $\begin{array}{l}193.0 \\
9.76-5 \\
1.22 \\
1.29 \\
1.32 \\
1.34\end{array}$ & $\begin{array}{r}60211.8 \\
2.12+2 \\
\\
1 . \\
1 . \\
1 .\end{array}$ & $\begin{array}{l}60018.8 \\
05 \stackrel{5.22+2}{\longrightarrow} \\
18 \\
22 \\
24\end{array}$ \\
\hline$M e^{4+}$ & $\stackrel{\Delta B}{A}$ & $\begin{array}{l}0.5 \\
1.0 \\
1.5 \\
2.0\end{array}$ & $\begin{array}{l}30291.5 \\
2.37-5 \\
\end{array}$ & $\begin{array}{l}29879.1 \\
1.31-1 \\
1.70 \\
1.78 \\
1.85 \\
1.92\end{array}$ & $\begin{array}{l}29181.4 \\
3.65-1 \\
\end{array}$ & $\begin{array}{r}63501.2 \\
4.21 \\
0 \\
0 \\
0 \\
0\end{array}$ & $\begin{array}{l}62803.5 \\
6.69-3 \\
848 \\
40 \\
38\end{array}$ & $\begin{array}{l}33622.1 \\
2.85 \\
0.581 \\
0.518 \\
0.550 \\
0.602\end{array}$ & $\begin{array}{l}412.4 \\
1.28-3 \\
0.244\end{array}$ & $\begin{array}{l}1110.1 \\
5.08-9 \\
0.122\end{array}$ & $\begin{array}{l}697.7 \\
4.59-3 \\
0.578\end{array}$ & $\begin{array}{r}87950.7 \\
2.37+3 \\
-1 \\
1 \\
1 .\end{array}$ & $\begin{array}{l}87253.0 \\
6.06+3 \\
19 \\
51 \\
53 \\
51\end{array}$ \\
\hline $\mathrm{Si}^{\circ}$ & $\begin{array}{l}\Delta B \\
\hat{T}\end{array}$ & & $\begin{array}{l}6298.9 \\
4.70-7\end{array}$ & $\begin{array}{l}6221.7 \\
7.93-4\end{array}$ & $\begin{array}{l}6075.7 \\
2.25-3\end{array}$ & $\begin{array}{l}15317.3 \\
3.13-2\end{array}$ & $\begin{array}{l}15171.2 \\
9.02-4\end{array}$ & $\begin{array}{l}9095.5 \\
1.14\end{array}$ & $\begin{array}{l}77.1 \\
8.25-6\end{array}$ & 223.2 & $\begin{array}{l}146.0 \\
4.21-5\end{array}$ & 33248.9 & 33102.9 \\
\hline$s^{2+}$ & $\stackrel{\Delta E}{\hat{T}}$ & $\begin{array}{l}0.5 \\
1.0 \\
1.5 \\
2.0\end{array}$ & $\begin{array}{l}11320 \\
5.82-6 \\
\end{array}$ & $\begin{array}{l}11023 \\
2.21-2 \\
9.07 \\
8.39 \\
8.29 \\
8.20\end{array}$ & $\begin{array}{l}10488 \\
5.76-2 \\
\end{array}$ & $\begin{array}{r}26866 \\
7.96-1 \\
1 \\
1 \\
1\end{array}$ & $\begin{array}{l}26331 \\
1.05-2 \\
\end{array}$ & $\begin{array}{l}15843 \\
2.22 \\
1.42 \\
1.88 \\
2.02 \\
2.08\end{array}$ & $\begin{array}{l}297.2 \\
4.72-4 \\
2.64 \\
2.59 \\
2.38 \\
2.20\end{array}$ & $\begin{array}{l}832.5 \\
4.61-8 \\
1.11 \\
1.15 \\
1.15 \\
1.14\end{array}$ & $\begin{array}{l}535.3 \\
2.07-3 \\
5.79 \\
5.81 \\
5.56 \\
5.32\end{array}$ & 59401 & 58866 \\
\hline $\mathrm{Cl}^{3+}$ & $\begin{array}{l}\Delta B \\
\hat{T}\end{array}$ & $\begin{array}{l}0.5 \\
1.0 \\
1.5 \\
2.0\end{array}$ & $\begin{array}{l}13767.6 \\
1.54-5 \\
\end{array}$ & $\begin{array}{l}13275.6 \\
7.23-2 \\
5.10 \\
5.42 \\
5.88 \\
6.19\end{array}$ & $\begin{array}{l}12425.7 \\
1.79-1 \\
\end{array}$ & $\begin{array}{l}32055.8 \\
2.47 \\
\longleftarrow 2\end{array}$ & $\begin{array}{l}31205.9 \\
2.62-2 \\
\longrightarrow\end{array}$ & $\begin{array}{l}18780.2 \\
2.80 \\
0.935 \\
1.39 \\
1.73 \\
1.92\end{array}$ & $\begin{array}{l}492.0 \\
2.14-3 \\
0.475\end{array}$ & $\begin{array}{l}1341.9 \\
2.70-7 \\
0.400\end{array}$ & $\begin{array}{l}849.9 \\
8.25-3 \\
1.50\end{array}$ & & \\
\hline$\Lambda^{4+}$ & $\begin{array}{l}\Delta \mathrm{B} \\
\hat{\mathrm{T}}\end{array}$ & $\begin{array}{l}0.5 \\
1.0 \\
1.5 \\
2.0\end{array}$ & $\begin{array}{l}16299.4 \\
3.50-5 \\
\end{array}$ & $\begin{array}{l}15535.5 \\
2.04-1 \\
4.37 \\
3.72 \\
3.52 \\
3.42\end{array}$ & $\begin{array}{l}14270.2 \\
4.76-1 \\
\end{array}$ & $\begin{array}{r}37148.6 \\
6.55 \\
\\
1 \\
1\end{array}$ & $\begin{array}{l}35883.3 \\
5.69-2 \\
17 \\
11 \\
03\end{array}$ & $\begin{array}{l}21613.1 \\
3.29 \\
1.26 \\
1.25 \\
1.24 \\
1.23\end{array}$ & $\begin{array}{l}763.9 \\
7.99-3 \\
0.257\end{array}$ & $\begin{array}{l}2029.2 \\
1.24-6 \\
0.320\end{array}$ & $\begin{array}{l}1265.3 \\
2.72-2 \\
1.04\end{array}$ & & \\
\hline
\end{tabular}

TABLE 6. Energy level geparations $\Delta B\left(\mathrm{~cm}^{-1}\right)$, traneition probabilitiee $A$ (eec ${ }^{-1}$ ) and effective collieion atrengthe $T\left(T_{e}\right)$ for the $a^{2}{ }^{2}{ }^{2}$ and nenp ${ }^{3}$ traneitione of the $C(n-2)$ and $S i(n-3)$ ieoelectronic eaquences. 


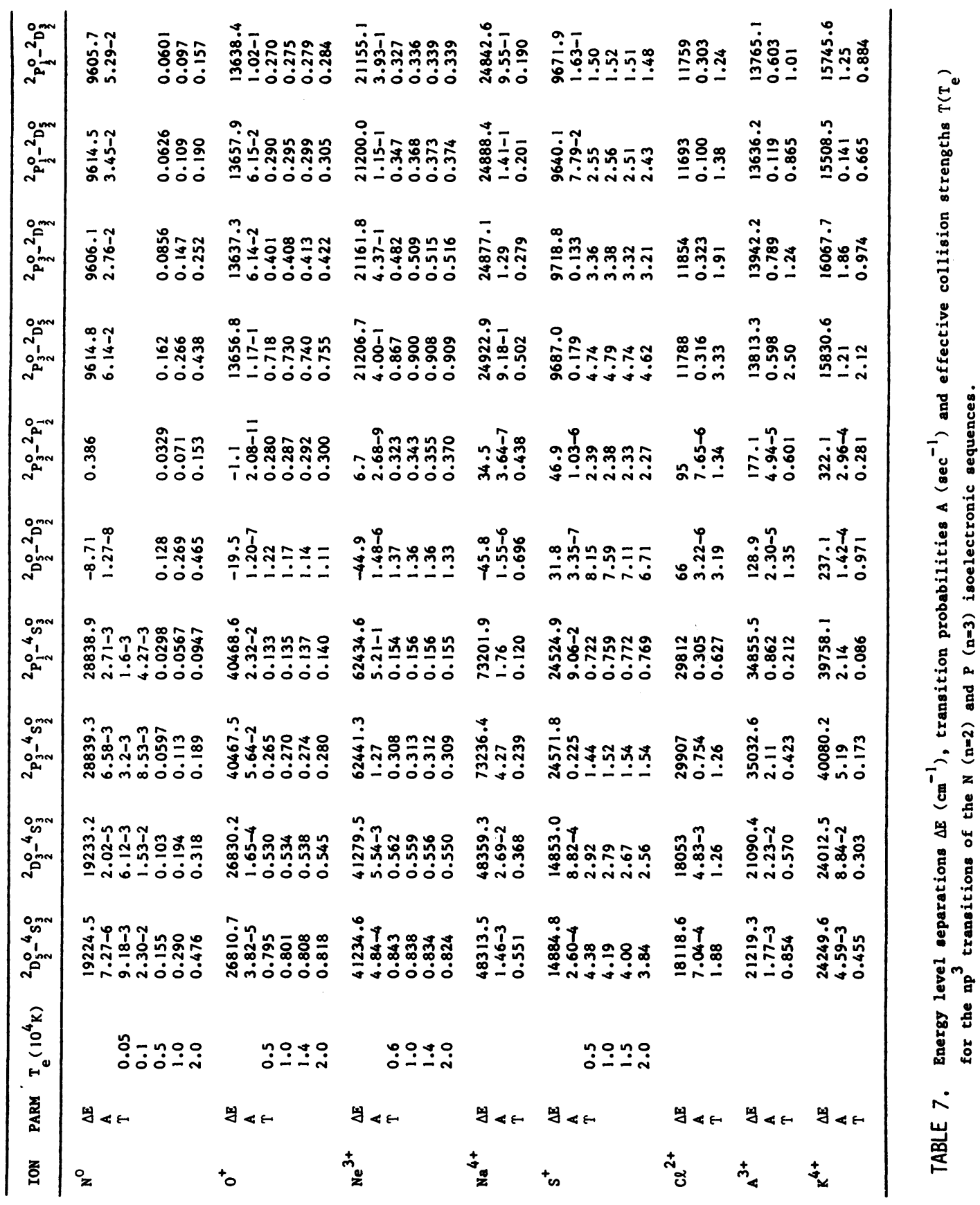




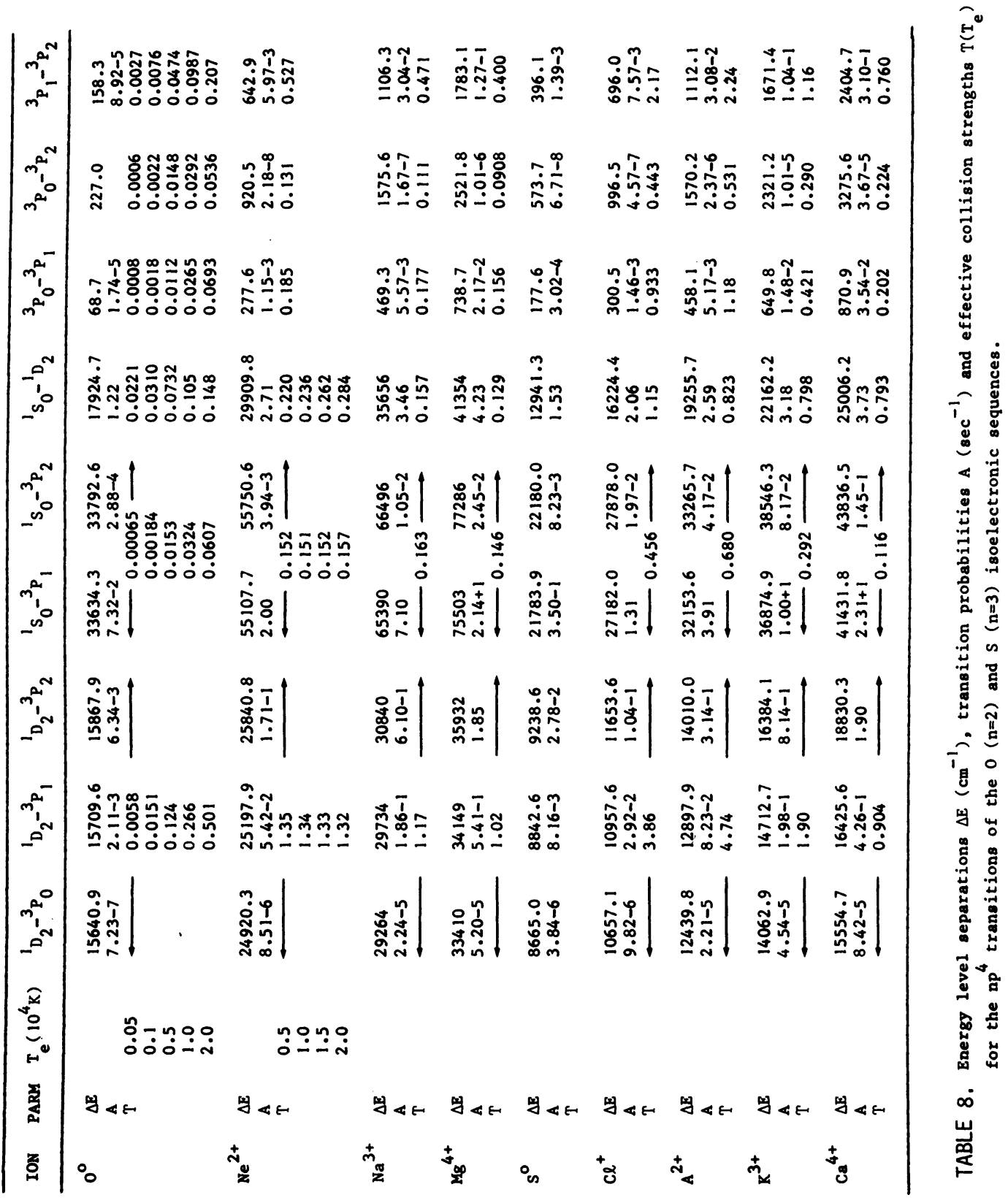




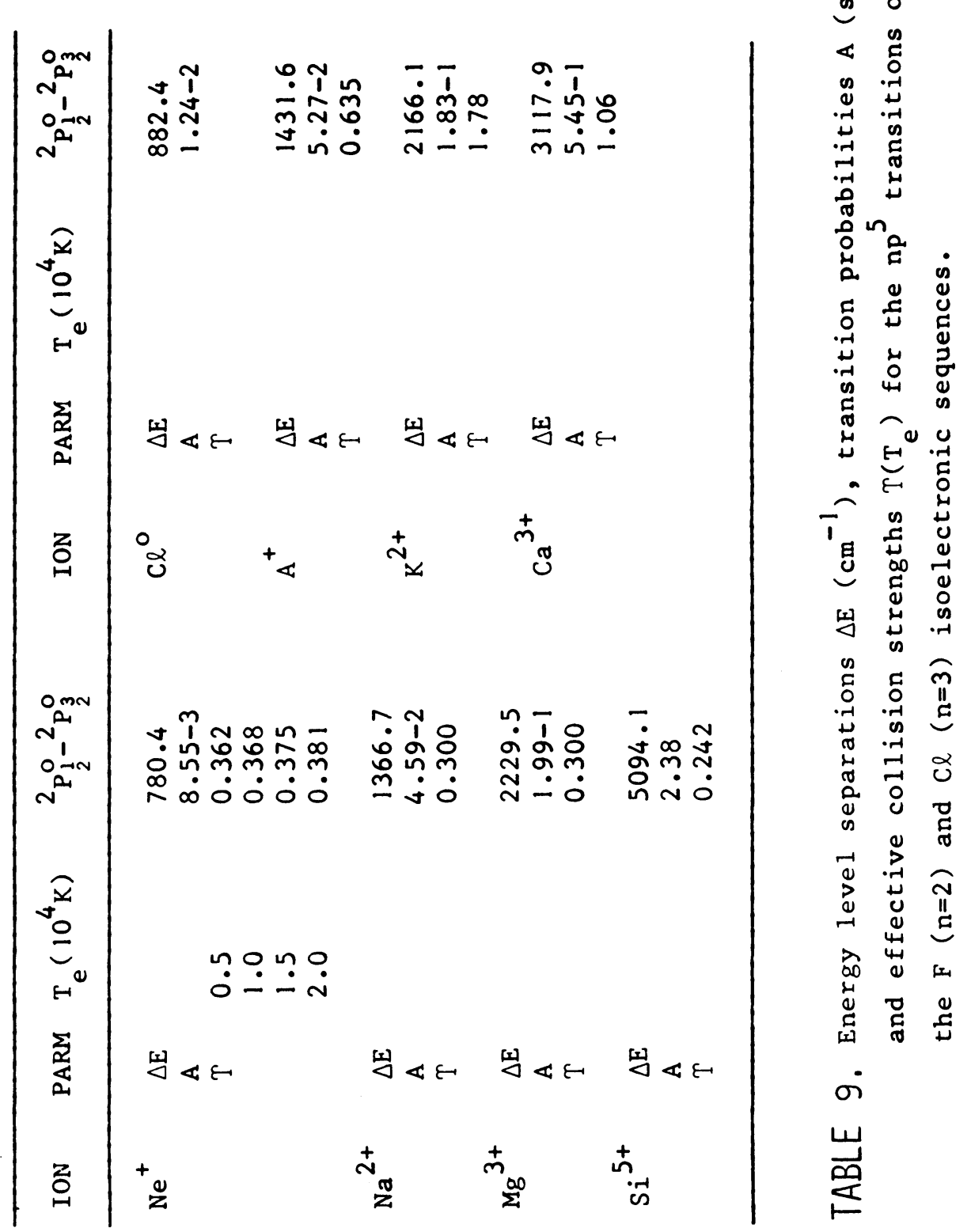


C. MENDOZA

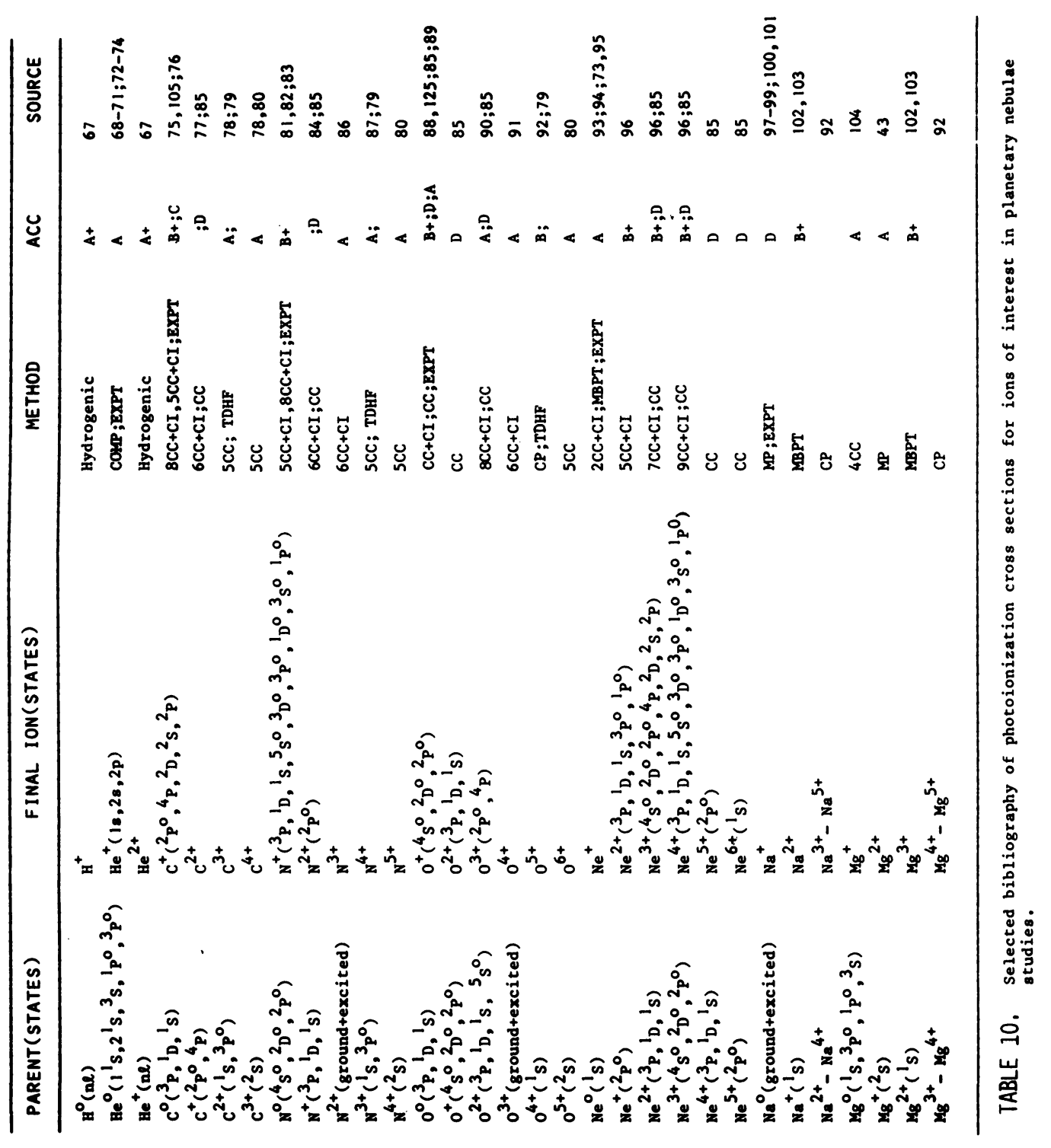




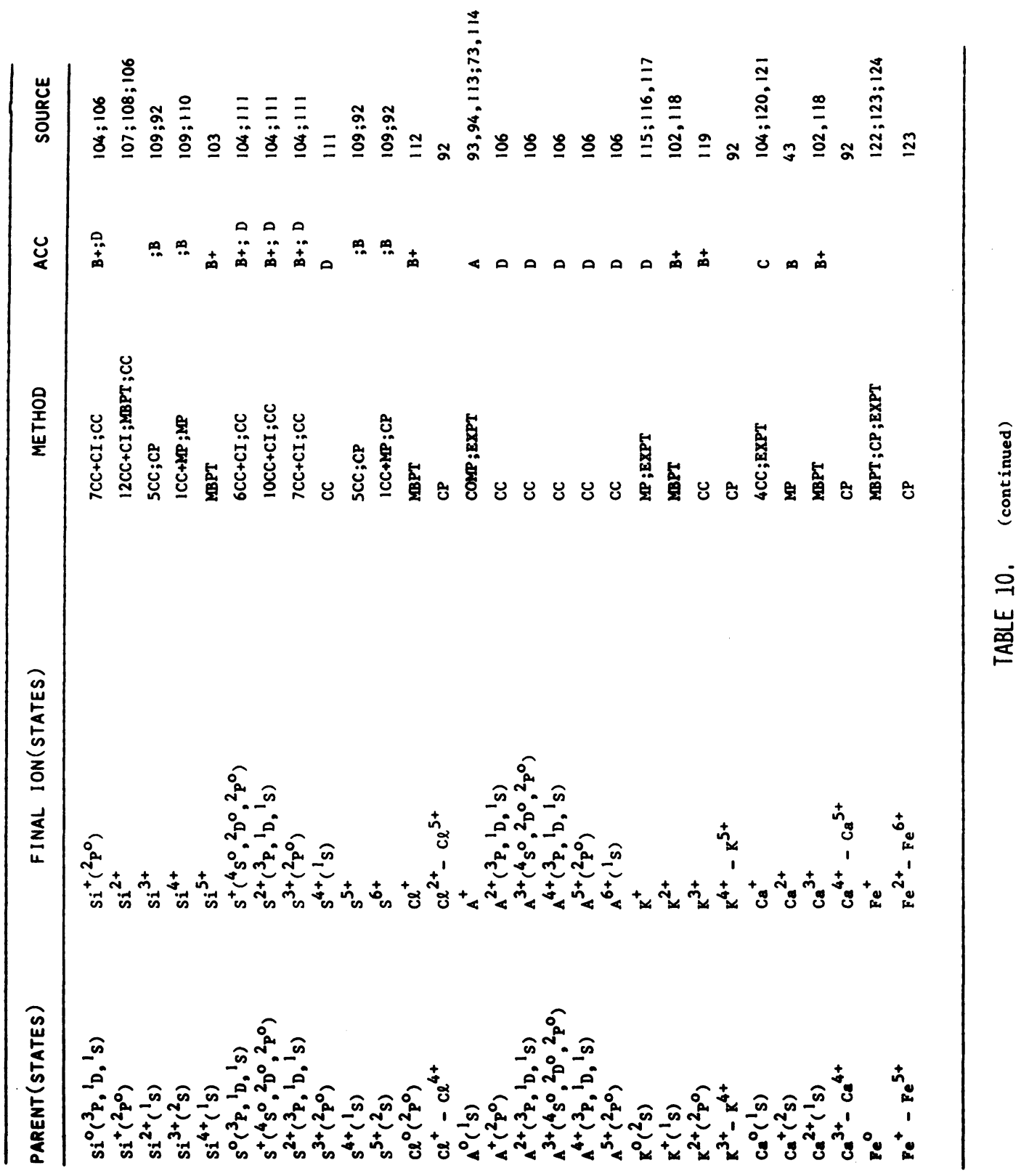




\section{REFERENCES}

1. Wiese WL, Smith MW and Glennon BM, 1966, "Atomic Transition Probabilities", Vo1.1 (NSRDS-NBS4).

2. Hata J and Grant IP, 1981, J.Phys.B, 14, 2111.

3. Drake GWF, 1979, Phys.Rev.A, 19, 1387.

4. Drake GWF and Dalgarno A, 1969, Astrophys.J., 157, 459.

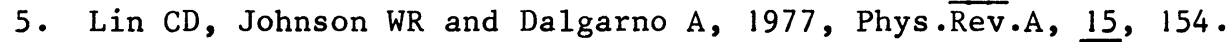

6. Berrington KA, Fon WC and Kingston AE, 1982, Mon.Not. R.Astr.Soc., $200,347$.

7. Nussbaumer $\mathrm{H}$ and Rusca C, 1979, Astron. Astrophys., 72, 129.

8. Péquignot D and Aldrovandi SMV, 1976, Astron. Astrophys., 50, 141.

9. Thomas LD and Nesbet RK, 1975, Phys.Rev.A., 12, 2378.

10. Nussbaumer H and Storey PJ, 1981, Astron. Astrophys., 96, 91.

11. Tambe BR, 1977, J.Phys.B, 10, L249.

12. Jackson ARG, 1973, Mon.Not.R.Astr.Soc., 165, 53.

13. Nussbaumer $\mathrm{H}$ and Storey PJ, 1978, Astron. Astrophys., 64, 139.

14. Dufton PL, Berrington KA, Burke PG and Kingston AE, 19 $\overline{78}$, Astron. Astrophys., 62, 111; + Daresbury Laboratory Data Bank.

15. Taylor PO, Gregory D, Dunn GH, Phaneuf RA and Crandal1 DH, 1977 , Phys.Rev.Lett., 39, 1256.

16. Gau JN and Henry RJW, 1977, Phys.Rev.A, 16, 986.

17. Zeippen CJ, 1982, Mon.Not.R.Astr.Soc., 198, 111.

18. Berrington KA and Burke PG, 1981, Planet. Space Sci., 29, 377.

19. Dopita MA, Mason DJ and Robb WD, 1976, Astrophys.J., 207, 102 .

20. Seaton MJ, 1975, Mon.Not.R.Astr.Soc.s 170, 475 .

21. Saraph HE, Seaton MJ and Shemming J, $\overline{969}$, Phil.Trans.R.Soc.A, 264,77 .

22. Hibbert A and Bates DR, 1981, Planet. Space Sci., 29, 263.

23. Nussbaumer $H$ and Storey PJ, 1979, Astron. Astrophys., 71 L5.

24. Nussbaumer $\mathrm{H}$ and Storey PJ, 1982, Astron. Astrophys., 109, 271.

25. Nussbaumer $\mathrm{H}$ and Storey PJ, 1979, Astron. Astrophys., $\overline{74}, 244$.

26. Osterbrock DE and Wallace RK, 1977, Astrophys.Lett., 19, 11.

27. van Wyngaarden WL and Henry RJW, 1976, J.Phys.B, $9,1 \overline{461}$.

28. Mendoza C and Zeippen CJ, 1982, preliminary results.

29. Le Dourneuf $M$ and Nesbet RK, 1976, J.Phys.B, 9 , L241.

30. Pradhan AK, 1976, Mon.Not.R.Astr.Soc., 177, 31.

31. Nussbaumer $\mathrm{H}$ and Storey PJ, 1981, Astron. Astrophys., 99, 177.

32. Baluja KL, Burke PG and Kingston AE, 1980, J.Phys.B, 13, 829; $1981,14,119$.

33. Aggarwal KM, Baluja KL and Tully JA, 1982, Mon.Not.R.Astr.Soc., in press.

34. Hayes MA, 1982, Mon.Not.R.Astr.Soc., 199, 49P; + private communication.

35. Pradhan AK, 1974, J.Phys.B, 7, L503.

36. Giles K, 1981, Mon.Not.R.Astr. Soc., 195, 63P.

37. Baluja KL, Burke PG and Kingston AE, 1980, J.Phys.B, 13, 4675.

38. Dufton PL, Doyle JG and Kingston AE, 1979, Astron. Astrophys., 78, 318; + Daresbury Laboratory Data Bank.

39. Butler K and Mendoza C, 1982, preliminary results.

40. Lin CD, Laughlin C and Victor GA, 1978, Astrophys.J., 220, 734 .

41. Clark REH, Magee NH, Mann JB and Merts AL, 1982, Astrophys.J., 254, 412.

42. Fabrikant II, 1974, J.Phys.B, 7, 91. 
43. Black JH, Weisheit JC and Laviana E, 1972, Astrophys.J., 177, 567. 44. Mendoza C, 1981, J.Phys.B, 14, 2465.

45. Mendoza C and Zeippen CJ, 1982, Mon.Not.R.Astr.Soc., 199, 1025.

46. Pindzola MS, Bhatia AK and Temkin A, 1977, Phys.Rev.A, 15, 35.

47. Nussbaumer H, 1977, Astron. Astrophys., 58, 291.

48. Mendoza C, 1982, preliminary results.

49. Baluja KL, Burke PG and Kingston AE, 1980, J.Phys.B, 13, L543; $1981,14,1333$.

50. Flower $\overline{\mathrm{DR}}$ and Nussbaumer $\mathrm{H}, 1975$, Astron. Astrophys., 42, 265.

51. Mendoza C and Zeippen CJ, 1982, Mon.Not.R.Astr.Soc., in press.

52. Mendoza C and Zeippen CJ, 1982, Mon.Not.R.Astr.Soc., 198, 127.

53. Mendoza C, 1982, J.Phys.B, to be published.

54. Dufton PL, Hibbert A, Kingston AE and Doschek GA, 1982, Astrophys.J., 257,338 .

55. Feldman U, Doschek GA and Bhatia AK, 1981, Astrophys.J., 250, 799 .

56. Giles K, 1980, Ph.D thesis, University of London.

57. Krueger TK and Czyzak SJ, 1970, Proc.R.Soc.Lond. A, 318, 531.

58. Taylor PO and Dunn GH, 1973, Phys.Rev.A, 8, 2304.

59. Grevesse $\mathrm{N}$, Nussbaumer $\mathrm{H}$ and Swings JP, $1 \overline{9} 71$, Mon.Not.R.Astr.Soc., $151,239$.

60. Nussbaumer $\mathrm{H}$ and Storey PJ, 1980, Astron. Astrophys., 89, 308.

61. Garstang RH, 1957, Mon.Not.R.Astr.Soc., 117, 393.

62. Garstang RH, Robb WD and Rountree SP, 1978, Astrophys.J., 222, 384 .

63. Ekberg JO and Edlén B, 1978, Physica Scripta, 18, 107.

64. Garstang RH, 1958, Mon.Not.R.Astr.Soc., 118, $5 \overline{72}$.

65. Nussbaumer $\mathrm{H}$ and Storey PJ, 1978, Astron. Astrophys., 70, 37.

66. Nussbaumer $\mathrm{H}$ and Storey PJ, 1982, Astron. Astrophys., in press.

67. Burgess A, 1964, Mem.R.Astr.Soc., 69, 1 .

68. Be11 KL and Kingston AE, 1970, J.Phys.B, 3 , 1433.

69. Jacobs VL, 1971 , Phys.Rev.A, 3, 289; 1974, 9, 1938.

70. Jacobs VL and Burke PG, 1972, J.Phys.B, 5, L67; 1972, 5, 2272.

71. Stewart AL, 1978, J.Phys.B, 11, L431; 1978, 11, 2449; 1979, 12, 401 .

72. Marr GV, 1978, J.Phys.B, 11, L 121 .

73. West JB and Marr GV, 1976, Proc.R.Soc.Lond.A, 349, 397.

74. Woodruff PR and Samson JAR, 1980, Phys.Rev.Let t., 45, 110;

1982, Phys.Rev.A, 25, 848.

75. Burke PG and Taylor KT, 1979, J.Phys.B, 12, 2971.

76. Cantú AM, Mazzoni M, Pettini M and Tozzi GP, 1981, Phys.Rev.A, 23, 1223 .

77. Drew JE and Storey PJ, 1982, in progress.

78. Drew JE and Storey PJ, 1982, J.Phys.B, 15, 2357.

79. Watson DK, Dalgarno A and Stewart RF, 1978, Phys.Rev.A, 17, 1928.

80. Pradhan AK, 1982, Phys.Rev.A, 25, 592.

81. Le Dourneuf M, Vo Ky Lan and Zeippen CJ, 1979, J.Phys.B, 12, 2449.

82. Zeippen CJ, Le Dourneuf M and Vo Ky Lan, 1980, J.Phys.B, $\overline{13}, 3763$.

83. Samson JAR and Cairns RB, 1965, J.Opt.Soc.Am., 55, 1035.

84. Nussbaumer $\mathrm{H}$ and Storey PJ, 1982, in progress.

85. Henry RJW, 1970, Astrophys.J., 161, 1153 .

86. Butler K, J.Phys.B, to be published.

87. Butler K, Lugo L and Mendoza C, 1982, J.Phys.B, to be submitted.

88. Taylor KT and Burke PG, 1976, J.Phys.B, 9, L353. 
89. Koh1 JL, Lafyatis GP, Palenius HP and Parkinson WH, 1978, Phys.Rev.A, 18,571 .

90. Saraph HE, J.Phys.B, 1982, to be published.

91. Saraph HE, 1980, J.Phys.B, 13, 3129.

92. Reilman RF and Manson ST, 1979, Astrophys.J.Supp1.Ser., 40, 815 ; $1981,46,115$.

93. Burke $\overline{\mathrm{PG}}$ and Taylor KT, 1975, J.Phys.B, 8, 2620.

94. Chang TN, 1977, Phys.Rev.A, 15, 2392.

95. Wuilleumier $F$ and Krause MO, 1979, J.Electron Spectrosc.Relat.Phenom., 15,15 .

96. Pradhan AK, 1979, J.Phys.B, 12, 3317; 1980,Mon.Not.R.Astr.Soc., 190, 5P.

97. Laughlin C, 1978, J.Phys.B, T, 1399.

98. Aymar M, Luc-Koenig E and Combet-Farnoux F, 1976, J.Phys.B, 9, 1279.

99. Aymar M, 1978, J.Phys.B, 11, 1413.

100. Hudson RD and Carter VL, 1967, J.Opt:Soc.Am., 57, 651.

101. Rothe DE, 1969, J.Quant.Spectrosc.Radiat.Transfer, 9, 49.

102. Chang TN, 1977, Phys.Rev.A, 16, 1171.

103. Chang TN and 01sen T, 1981, Phys.Rev.A, 24, 1091.

104. Mendoza C, 1982, to be published.

105. Hofmann H and Trefftz E, 1980, Astron. Astrophys., 82, 256.

106. Chapman RD and Henry RJW, 1972, Astrophys.J., 173, 243.

107. Le Dourneuf $M$ and Zeippen $C J, 1982$, in progress.

108. Daum GR and Kelly HP, 1976, Phys.Rev.A, 13, 715.

109. Mendoza C and Zeippen CJ, 1982, in progress.

110. Shevelco VP, 1974, Opt.Spektrosk., 36, 14.

111. Chapman RD and Henry RJW, 1971, Astrophys.J., 168, 169.

112. Brown ER, Carter SL and Kelly HP, 1980, Phys.Rev.A, 21, 1237.

113. Kel1y HP and Simons RL, 1973, Phys.Rev.Lett., 30, $52 \overline{9}$.

114. Madden RP, Ederer DL and Codling K, 1969, Phys.Rev., 177, 136.

115. Weisheit JC, 1972, Phys.Rev.A, 5, 1621

116. Sandner W, Gallagher TF, Safinya KA and Gounand F, 1981, Phys.Rev.A, 23,2732 .

117. Hudson RD and Carter VL, 1965, Phys.Rev., 139, A 1426.

118. Chang TN, 1979, Phys.Rev.A, 20, 291.

119. Combet-Farnoux F, Lamoureux $\bar{M}$ and Taylor KT, 1978, J.Phys.B, $11,2855$.

120. Carter VL, Hudson RD and Breig EL, 1971, Phys.Rev.A, 4, 821.

121. McIlrath TJ and Sandeman RJ, 1972, J.Phys.B, 5, L217.

122. Kelly HP and Ron A, 1972, Phys.Rev.A, 5, 168.

123. Reilman RF and Manson ST, 1978, Phys.Rev.A, 18, 2124.

124. Lombardi GG, Smith PL and Parkinson WH, 1978, Phys.Rev.A, 18, 2131.

125. Pradhan AK and Saraph HE, 1977, J.Phys.B, 10, 3365.

126. Aggarwa1 KM, 1982, Mon.Not.R.Astr.Soc., submitted 